\title{
Designing for Reliability and Robustness in International Space Station Exercise Countermeasures Systems
}

\author{
Cherice Moore ${ }^{1}$ \\ Johnson Space Center, National Aeronautics and Space Administration, Houston, TX 77058 \\ Randall Svetlik ${ }^{2}$ \\ ERC, Inc., Houston Texas, 77058 \\ Antony Williams ${ }^{3}$ \\ Jacobs Engineering, Houston Texas, 77058
}

As spaceflight durations have increased over the last four decades, the effects of microgravity on the human body have become far better understood, as have the exercise countermeasures. Through use of a combination of aerobic and resistive exercise devices, today's astronauts and cosmonauts are able to partially counter the losses in muscle strength, aerobic fitness, and bone strength that otherwise might occur during their missions on the International Space Station (ISS).

Since 2000, the ISS has employed a variety of exercise equipment used as countermeasures to these risks. Providing reliable and available exercise systems has presented significant challenges due to the unique environment. In solving these, lessons have been learned that can inform development of future systems.

\section{INTRODUCTION}

Long duration spaceflight has a negative effect on the human body, and exercise countermeasures are used on-orbit to minimize bone and muscle loss, combatting these effects. Given the importance of these hardware systems to the health of the crew, this equipment must maintain high availability. Designing spaceflight exercise hardware to meet high reliability and availability standards has proven to be challenging since crewmembers have been living on ISS, beginning in 2000. Furthermore, restoring operational capability after a failure is clearly time-critical, but can be problematic given the challenges of troubleshooting the problem from 220 miles away.

Several best-practices have been leveraged in seeking to maximize availability of these exercise systems, including designing for robustness, implementing diagnostic instrumentation, relying on user feedback, and providing ample maintenance and sparing. These factors have enhanced the reliability of hardware systems, and therefore have contributed to keeping the crewmembers healthy upon return to Earth. This paper will review the failure history for three countermeasure systems with the intent of identifying lessons learned that can help improve future systems. Specifically, the Treadmill with Vibration Isolation and Stabilization System (TVIS), Cycle Ergometer with Vibration Isolation and Stabilization System (CEVIS), and the Advanced Resistive Exercise Device (ARED) will be reviewed and analyzed, and conclusions identified in

${ }^{1}$ Exploration Exercise Technology Development Manager, Flight Systems Branch hopes of improving future exercise hardware designs. These lessons learned, paired with thorough testing, offer a path towards reduced system down-time.

\section{COUNTERMEASURES SYSTEMS (CMS) OVERVIEW}

When placed in a microgravity environment the human body begins to experience several changes. Among these are a loss of bone, muscle mass, and aerobic capacity due to the much lighter than typical loads seen by the structure of the body when compared to life on Earth. For a healthy individual in space for a short period of time these losses are typically significant and are quickly remedied upon return to the ground. However, for crewmembers that remain on-orbit for an extended period of time, the cumulative loss of bone, muscle, and aerobic capacity can potentially result in serious negative health effects. These effects can include an increased risk of kidney stones due to secreted calcium from bones, a loss of ability to tolerate Soyuz landing, a loss of ability to perform Extravehicular Activities (EVA), an increased risk of bone fracture and osteoporosis upon return to Earth, a loss of ability to perform rapid safing and emergency egress activities, and a significant increase in the amount of time required to complete rehabilitation after returning to the ground.

\section{A. TVIS}

The TVIS system was first deployed in 2000 and provided aerobic conditioning by simulating Earth's gravitational force (1-g) running and walking on a treadmill in the microgravity environment of the ISS. With appropriate loading, treadmill exercise also provided impact forces and helped maintain neuromuscular and postural mechanisms.

The Vibration Isolation and Stabilization (VIS) System minimized the transfer of dynamic forces caused by treadmill exercise to the structure of the Russian Service Module (SM) and other parts of the ISS, while at the same time maintaining a stable running/walking surface. The VIS components were software controlled and worked in unison to counteract the imparted pitch and roll torques and to provide a flexible mechanical connection to the ISS by stabilizing TVIS against excessive motion caused by exercise. The active components of the VIS System were the gyroscope, four linear slide-mass

\footnotetext{
${ }^{2}$ Deputy Project Manager, Advanced Resistive Exercise Device.

${ }^{3}$ Chief Engineer, SE\&I, Engineering Department
} 
stabilizers, four motor controllers and a VIS controller. The running surface of the treadmill was used in much the same way as any conventional terrestrial treadmill, except the user was held to its surface by the Series Bungee System (SBS) and/or the Subject Load Device (SLD), which each attached to the Treadmill Harness to counter the microgravity environment. TVIS served on ISS until 2013, at which time it was replaced with the Russian BD-2 treadmill. Figure 1 shows a schematic of the TVIS, while Figure 2 shows the TVIS in use on ISS, including the SBS. [1]

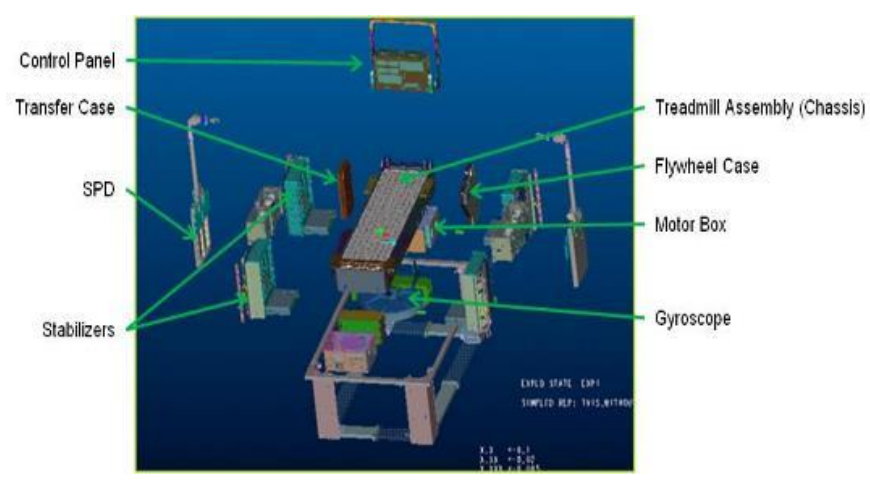

Figure 1. TVIS System

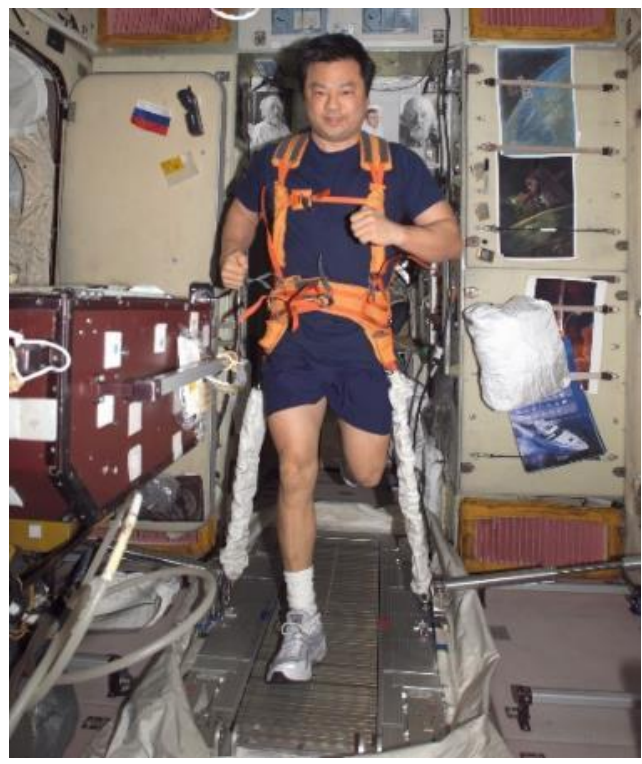

Figure 2. TVIS in use on ISS

\section{B. CEVIS}

While the TVIS provides the ability to run and walk in microgravity, the CEVIS system provides cycling aerobic exercise, in either a recumbent or upright posture. CEVIS is also used for pre-breathe operations prior to an EVA, periodic fitness evaluations, and pre-landing fitness evaluations. The CEVIS Ergometer can be controlled electronically via protocols in a control panel, or it can be manually controlled by the subject. The Control Panel displays real-time subject data, including heart rate, speed, and workload. Two Inertial Vibration Isolation and Stabilization (IVIS) Boxes are attached at either end of the Ergometer and provide passive mechanical counter-inertia to the forces imparted by the riding subject. These minimize forces imparted into the CEVIS frame and hence into the ISS structure. CEVIS was deployed on ISS in March 2001 and continues in service currently. Figures 3 and 4 show the CEVIS schematic and the CEVIS in use in an recumbent posture, respectively. [2]

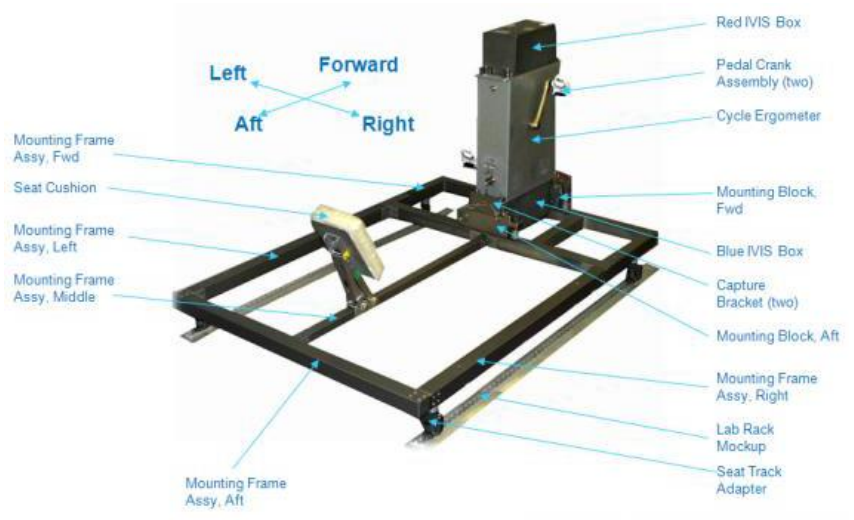

Figure 3. CEVIS System

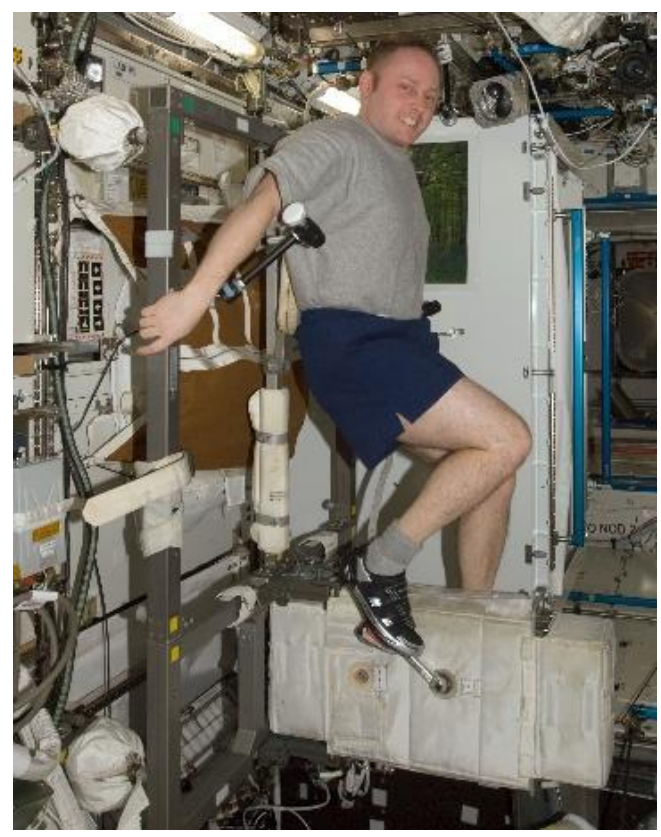

Figure 4. CEVIS in use on ISS

\section{ARED}

The ARED is the primary resistive exercise device on ISS utilizing two vacuum cylinders to provide workload. The ARED system incorporates multiple improvements to its predecessor, the Interim Resistive Exercise Device, including increased load from 320 to 600 pounds, a more desirable load characterization, vibration isolation, lower maintenance requirements, and greater ease of use and reliability. It provides bar and cable (rope) exercises, much like ground gym equipment, and it contains an inertial flywheel system to simulate the feel of $1-\mathrm{g}$ free-weights. ARED was deployed in January 2009 and continues in service currently. Figure 7 shows the ARED in use on ISS. [3] 


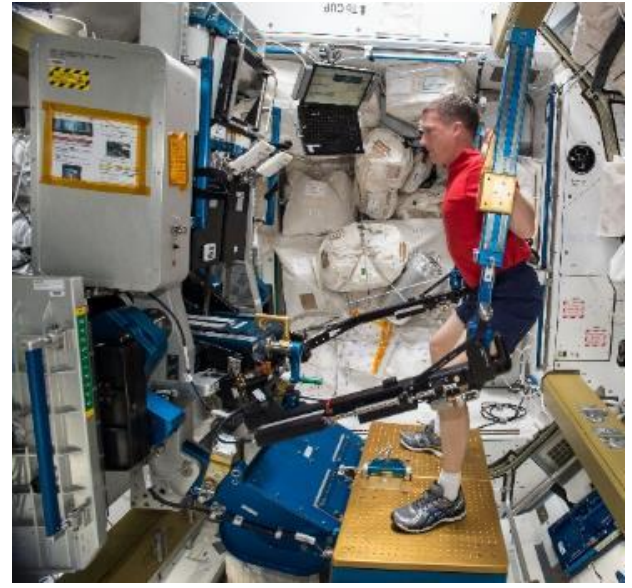

Figure 5. ARED in use on ISS

\section{DEFINITIONS AND CONCEPTS FOR RELIABILITY \& ROBUSTNESS TERMINOLOGY}

The following definitions and references are provided to provide a context for the reliability discussions that follow.

Table 1. R\&M Definitions

\begin{tabular}{|l|l|}
\hline \multicolumn{1}{|c|}{ Term } & \multicolumn{1}{c|}{ Definition } \\
\hline Reliability & $\begin{array}{l}\text { Probability that a given item will perform its } \\
\text { intended function with no failures for a given } \\
\text { period of time under a given set of conditions [4] }\end{array}$ \\
\hline Availability & $\begin{array}{l}\text { Probability that an item will perform its intended } \\
\text { function at a given time, under designated } \\
\text { operating conditions, and with a designated } \\
\text { support environment [5] }\end{array}$ \\
\hline Risk & $\begin{array}{l}\text { The combination of the probability that a } \\
\text { program or project will experience an undesired } \\
\text { event (some examples include a cost overrun, } \\
\text { schedule slippage, safety mishap, health } \\
\text { problem, malicious activities, environmental } \\
\text { impact, or failure to achieve a needed scientific } \\
\text { or technological breakthrough or mission } \\
\text { success criteria) and the consequences, impact, } \\
\text { or severity of the undesired event, were it to } \\
\text { occur. Both the probability and consequences } \\
\text { may have associated uncertainties. [6] }\end{array}$ \\
\hline
\end{tabular}

Designing for reliability does not only occur in the design phase of a project, but it starts during requirements definition and continues into the operational phase. Figure 6 depicts the National Aeronautics and Space Administration (NASA) system development life cycle model, and Table 2 lists areas and approaches for addressing reliability during various life cycle phases.

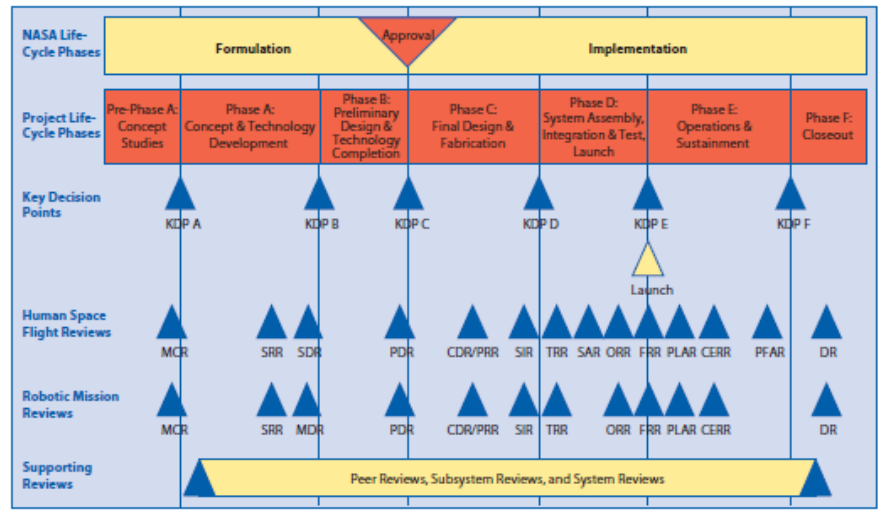

Figure 6. NASA Life Cycle Phases

Table 2. Reliability Concepts [7]

\begin{tabular}{|c|c|}
\hline Phase & R\&M Activity \\
\hline $\begin{array}{l}\text { Concept of } \\
\text { Operations } \\
\text { (CONOPS) } \\
\text { Definition }\end{array}$ & $\begin{array}{ll} & \text { Define maintenance concept } \\
\text { - } & \text { Defines reliability needs }\end{array}$ \\
\hline $\begin{array}{l}\text { System } \\
\text { Requirement } \\
\text { s Definition }\end{array}$ & 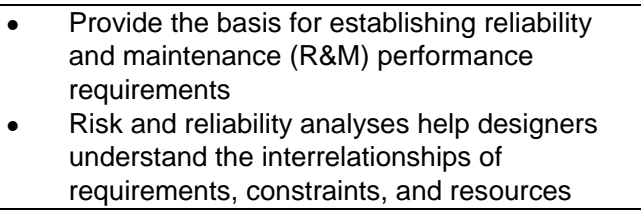 \\
\hline Analysis & $\begin{array}{ll}- & \text { Event sequence diagrams/event trees } \\
\text { - } & \text { Failure Modes and Effects Analyses } \\
\text { - } & \text { Qualitative top-down logic models } \\
\text { - } & \text { Quantitative logic models (probabilistic risk } \\
\text { - } & \text { assessment) } \\
\text { - } & \text { Reliability block diagrams } \\
\text { - } & \text { Human reliability analysis } \\
\text { - } & \text { Probabilistic structural analysis } \\
\text { - } & \text { Sparing/logistics models } \\
\end{array}$ \\
\hline Design & $\begin{array}{ll}\text { - } & \text { Zero Failure Design, Fault Tolerance, } \\
& \text { Derating, Durability, Safety Margins } \\
\text { - } & \text { Design Reviews } \\
\text { - } & \text { Reliability Allocation, Modeling, and Prediction } \\
\text { - } & \text { Design Failure Mode, Effects, and Criticality } \\
& \text { Analysis } \\
\text { - } & \text { Fault Tree Analysis } \\
\text { - } & \text { Sneak Circuit Analysis } \\
\text { - } & \text { Worst-Case Analysis } \\
\text { - } & \text { Statistical Analysis } \\
\text { - } & \text { Ruality Function Deployment } \\
\text { - } & \text { Fault Detection, Isolation and Recovery } \\
& \text { (FDIR) Capability } \\
\text { - } & \text { Environmental and stress testing, burn-in } \\
\end{array}$ \\
\hline Manufacture & $\begin{array}{ll}- & \text { Process Failure Mode, Effects, and Criticality } \\
& \text { Analysis } \\
\text { - } & \text { Statistical Process Control }\end{array}$ \\
\hline Testing & $\begin{array}{ll}\text { - } & \text { R\&M Performance Requirements Verification } \\
\text { - } & \text { Reliability testing (Typical testing regime for } \\
& \text { ISS flight hardware [8] } \\
\text { - } & \text { Functional/Integration tests } \\
\text { - } & \text { Burn in, Vibration, Thermal Cycle, Pressure, } \\
& \text { Radiation, EMI, Human Factors } \\
\text { - } & \text { Stress, Thermal, Materials Analysis } \\
\text { - } & \text { EEE Parts and Derating Analyses } \\
\end{array}$ \\
\hline Operations & $\begin{array}{ll} & \text { Failure Reporting, Analysis, And Corrective } \\
& \text { Action System }\end{array}$ \\
\hline
\end{tabular}




\section{$I V$. RELIABILITY HiSTORY}

In order to discuss the reliability of each system, this paper will address the following areas:

1. Performance History

2. Failure History

3. Success Stories - Reliable Components

Although the focus of this paper is the failures and the resulting lessons learned, it is important to note that all three systems maintained very high availability rates over their lifetimes, as shown in Table 3.

Table 3. CMS Operational Availability

\begin{tabular}{|l|l|}
\hline \multicolumn{1}{|c|}{ System } & \multicolumn{1}{c|}{ Availability } \\
\hline ARED & $>98 \%$ \\
\hline TVIS & $96.8 \%$ \\
\hline CEVIS & $>99 \%$ \\
\hline
\end{tabular}

\section{A. ARED}

\section{Performance History}

ARED has a history of being a very reliable piece of equipment, especially given the usage rates on ISS, and even the major failures have typically deferred exercise only one or two days at most.

There are only a select few types of failures that will take ARED to a NO-GO state, as seen in Table 4 below. ARED exercise in any form would not be able to be performed until the broken part is replaced.

On the other hand, certain types of historical failures have been quickly recoverable, and the only factor that would delay ARED exercise would be the available crew time to perform the replacement or workaround activity.

Table 4 NO-GO and Failures with Operational Restrictions - ARED

\begin{tabular}{|c|c|}
\hline NO-GO Failures & $\begin{array}{l}\text { Failures with Operational } \\
\text { Restrictions }\end{array}$ \\
\hline $\begin{array}{ll}- & \text { Structural, Push-in-Place } \\
\text { (PIP) Pin, or Bearing } \\
\text { Failure } \\
\text { - } \quad \text { VIS component failure } \\
\text { - }\end{array}$ & $\begin{array}{l}\text { - Upper stop cable - no upper } \\
\text { stop lifts, i.e. heel raises or } \\
\text { squats } \\
\text { - Detent Plates worn - Cannot } \\
\text { perform bar exercise, cable } \\
\text { only } \\
\text { - } \\
\text { AIB - No instrumented data }\end{array}$ \\
\hline
\end{tabular}

\section{Failure History}

This section details the important ARED failures that demonstrated lessons learned in reliability.

\section{a) Crank Handle}

The ARED arm base assembly is the connection point between the bar or cable actuated by the crewmember to the piston shafts that supply the load. It allows the user to adjust the load by turning a crank handle attached to the end of a screw assembly. The crank handle serves as the crewmember interface to the load adjustment mechanism, and it allows the crewmember to select the amount of resistance by adjusting the position of the slider (Figure 8). The crank handle requires two auto-locking mechanisms to be disabled in order to adjust the resistance. First, the crank handle is spring-loaded to prevent inadvertent slipping of the crank load adjustment mechanism. Second, a trigger mechanism in the handle requires the disengagement by the crewmember prior to adjusting the load. The assembly consists of a stack of keyed parts that transmit the load to the adjustment mechanism (Figure 7) [3].

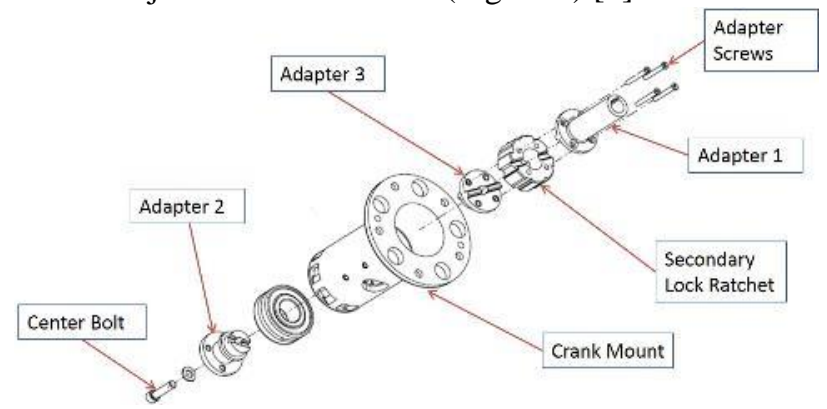

\section{Figure 7. Exploded View of ARED Crank Handle Internal Mechanism}

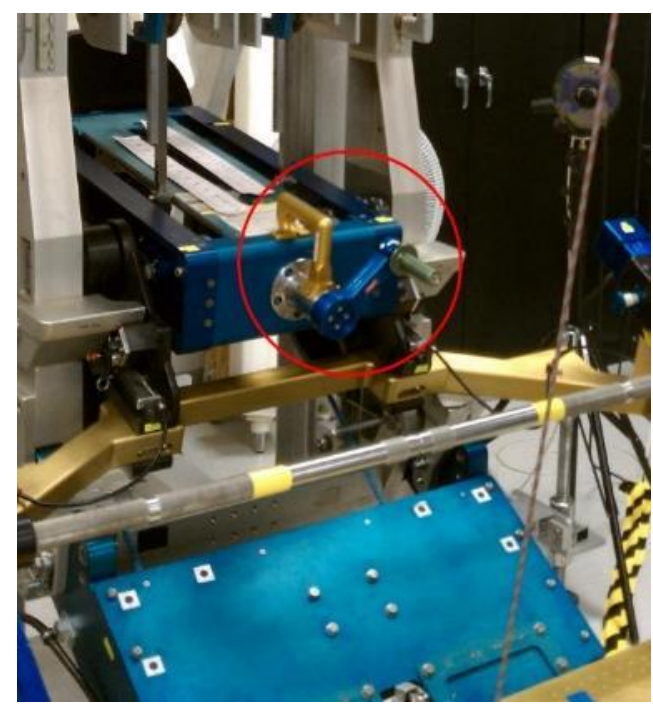

Figure 8. ARED Crank Handle Location

The first series of ARED crank handle failures occurred at approximately 2 years of service in January 2012. Until then, no maintenance had been required or performed on it. The crew experienced spontaneous increase in dialed load while turning the crank handle, which is only possible if something in the stack of keyed parts or safety latches were to fail. The crew removed the crank handle from the load adjustment unit and found that the key that connects adapter 1 to the ball screw shaft was sliding into adapter 1 and disengaging the ball screw. This was remedied by inserting a small socket into adapter 1 behind the key to prevent it from sliding. Next the crew discovered the locking pin in the crank handle was worn down to where it would not engage the catch reliably. Another successful workaround was devised to replace the pin with a bolt. The third and final failure on this unit occurred when, again, spontaneous load increase occurred. When the crew disassembled the crank handle the final time, they found that the keyed interface 
between adapters 2 and 3 had sheared off, allowing the stack to spin freely and bypassing the protective latch mechanism. ARED was declared NO GO until a replacement was delivered. The socket inside adapter 1 was reapplied to the replacement unit and continues to be in use.

The second crank handle unit had an anomaly occur in July 2013. The crew reported the handle was loose. Upon inspection they determined that the center bolt was loose. The ARED engineers developed a procedure to properly tighten the bolt, and a routine maintenance activity was added every 6 months to prevent the center bolt from loosening again.

The second crank handle unit remained in service until a failure in October 2014. The crew reported a slight spontaneous load increase, so troubleshooting was conducted on-orbit. The crew found that three of four fasteners that connect adapters 1 and 3 were completely backed out and free-floating in the assembly housing. The crank handle was replaced with a spare and returned to the ground for assessment, where it was discovered not only had the fasteners backed out, but the keyed interface between adapters 2 and 3 was sheared off. This damage can be seen in Figure 9 below. This last failure initiated a change request to redesign the internal parts of the crank handle to eliminate possibilities for fasteners becoming loose or interfaces from fracturing [9-14].

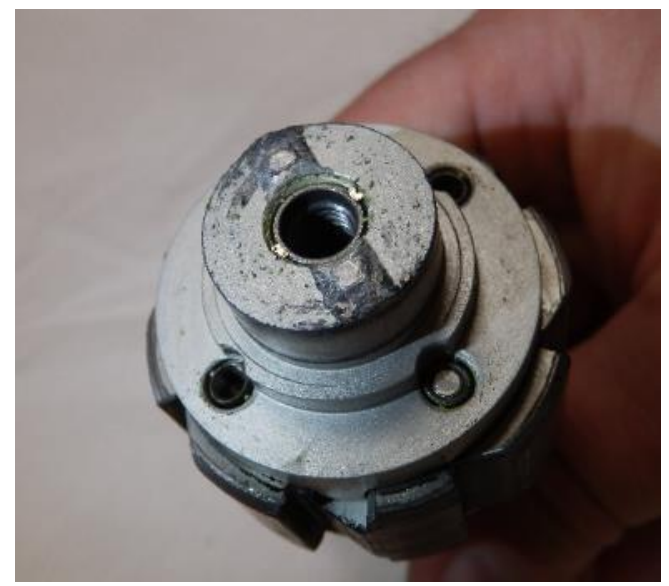

Figure 9. Adapter 3 Key Damage

Table 5. Timeline for Adapter Key

\begin{tabular}{|l|l|}
\hline \multicolumn{1}{|c|}{ Date } & \multicolumn{1}{c|}{ Event } \\
\hline Jan 2012 & Shear key back-out \\
\hline Jan 2012 & Lock pin failure \\
\hline Jan 2012 & Adapter failure key sheared off \\
\hline Jan 2013 & Center bolt loose \\
\hline Oct 2014 & $\begin{array}{l}\text { Adapter screws loose and adapter } \\
\text { key sheared off }\end{array}$ \\
\hline
\end{tabular}

\section{b) Dashpot Failures}

The ARED Vibration Isolation System (VIS) has three major components: X-rotation, Y-translation, and Z-translation (Figures 12 and 14). After approximately 6 months of use, the crew identified damage to X-rotation dashpots, which was not previously seen in ground life cycle testing, including a separated rod end and cracked glass housing. ARED was declared NO GO, and the damaged dashpots were replaced approximately a month later after spares arrived on board. It was determined that the rod end pulled out of the swage fitting and the paddle of the dashpot impacted the loose end, causing it to bottom out and crack the glass housing (Figure 13). Three subsequent failures occurred over the next 3 years, all exhibiting the same failure mode, but spares were prepositioned on ISS to provide immediate recovery of operations. A design change was initiated on the interface of the rod end and swage to provide a stronger connection. This design has since been life-cycle tested and certified for flight and has proven to survive cycles that equate to the end of the ISS life currently set to 2024. Spares will still be flown to minimize risk of system down-time [15].

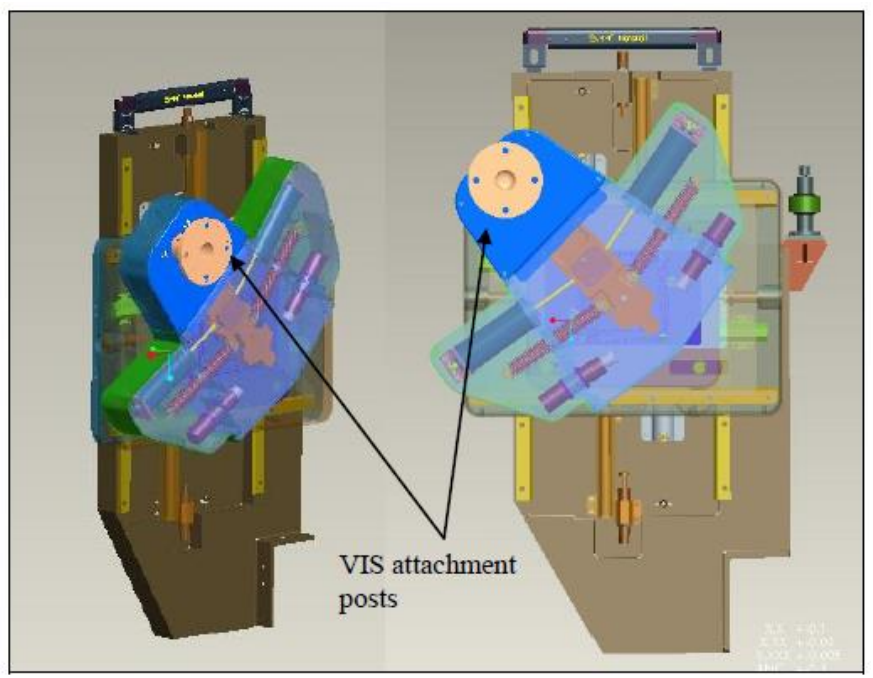

Figure 10. ARED VIS System
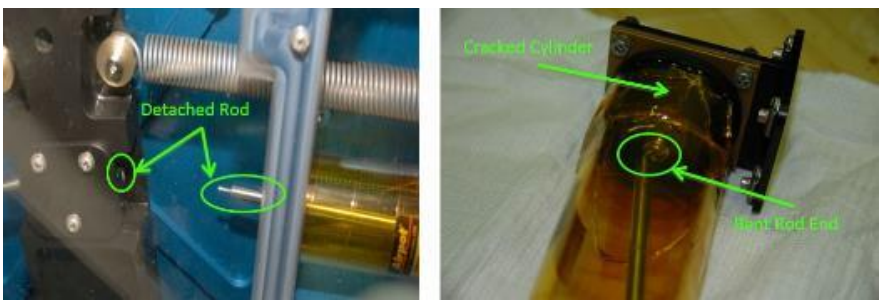

Figure 11. -Rotation Dashpot Rod End Failure (left) and X-Rotation Dashpot Glass Breakage (right)

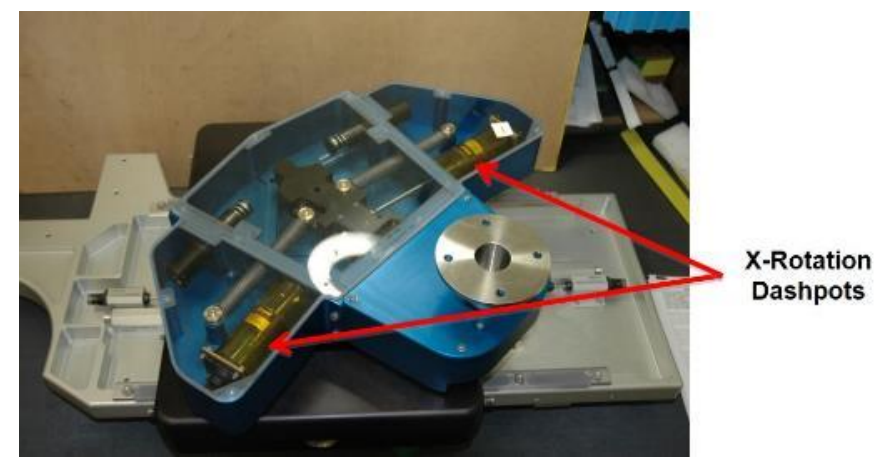

Figure 12. X-Rotation Dashpot Position

c) ARED Instrumentation Board (AIB) Failure

The ARED instrumentation consists of 14 individual sensors 
located within the ARED system. The signals produced by these sensors are processed by the AIB, which contains filters, data acquisition modules, and universal serial bus (USB) hub electronics for translation and communication of the sensor signals. The AIB outputs the information to the ARED software for recording and displaying to the crewmember.

In August 2011, the crew received an error message indicating that the AIB data acquisition board was not functioning. It could not be recovered via power cycle, and no spares were on board. Ground testing with like units pointed to a failure of the commercial USB hub within the AIB. A design modification was initiated to make the USB hub replaceable onorbit by the crew, and the new design of AIB was certified and flown in 2014 [16].

\section{Success Stories - Reliable Components}

Even with the history of failures, ARED has several components that have been extremely reliable. The following are examples of designing and testing to reach a reliable state.

\section{a) Polyester Exercise Rope}

The polyester exercise rope experienced an initial failure with the splice pulling out during a zero-load condition, but since a lock stitch was added to the design, it has operated without failure for 2 years on-orbit. This was a significant increase in service life over the Vectran exercise rope, which required replacement every 6-8 weeks. The success of the polyester rope can be attributed to thorough life-cycle testing, a scatter factor of 2 , and involvement with industry rope experts in the design.

\section{b) Cable Arm Ropes}

Although the ARED cable arm ropes have to be replaced approximately every 3-4 months, they have never experienced an on-orbit failure, and they continue to fail in a consistent fashion during life-cycle testing where they are used almost constantly in the ARED life-cycle test rig. Success and consistency in the design can be attributed to thorough lifecycle testing, a scatter factor of 2 , and involvement with industry rope experts in the design.

\section{c) Structural}

ARED structure has never experienced a failure to date, which can be attributed to materials selection and thorough analysis to show positive margins of safety on structural components.

\section{B. TVIS}

\section{Performance History}

Compared to other CMS hardware systems, TVIS spent a considerable amount of time on-orbit in a NO-GO configuration with components/orbital replacement units (ORUs) broken and waiting for replacement parts. Life-cycle testing was not performed on the original TVIS components, so when a part failed, there were typically no spares on-obit, and many of the failures required a redesign to fix the problem. A large contributor to down-time was that the U.S. was dependent solely on Russian cargo flights from 2003-2005 while the Space Shuttle Columbia accident investigation was underway. This created a longer waiting period for parts to arrive on ISS because TVIS was designed for replacement of large ORUs that could not be accommodated in the limited stowage available on Russian Progress vehicles.

Most ORU failures that occurred on TVIS took it to a NO-GO state, as seen in Table 6 below._TVIS exercise in any form would not be able to be performed until the broken part was replaced. Certain types of historical failures were quickly recoverable, and the only factor that would delay TVIS exercise would be the available crew time to perform the replacement or workaround activity.

Table 6 NO-GO and Failures with Operational Restrictions - TVIS

\begin{tabular}{|l|l|}
\hline \multicolumn{1}{|c|}{ NO-GO Failures } & \multicolumn{1}{c|}{$\begin{array}{c}\text { Failures with Operational } \\
\text { Restrictions }\end{array}$} \\
\hline - $\begin{array}{l}\text { Chassis - Belt/Slat failure } \\
\text { Gyroscope or Stabilizer } \\
\text { failure }\end{array}$ & - $\begin{array}{l}\text { SLD - use SBS instead } \\
\text { PC Card - Active (no } \\
\text { data)/Manual/Passive mode } \\
\text { Control Panel / EB - } \\
\text { stabilization goes down } \\
\text { Drivetrain - Motor box } \\
\text { (lockup NO GO - spun } \\
\text { freely - passive mode), } \\
\text { transfer case, flywheel } \\
\text { case } \\
\text { Roller Bearing failures - } \\
\text { roller could be removed } \\
\text { and resume }\end{array}$ \\
\hline
\end{tabular}

\section{Failure History}

This section details the important TVIS failures that demonstrated lessons learned in reliability.

\section{a) Chassis}

The treadmill chassis (Figure 15) consisted primarily of a four-sided rectangular aluminum box with two long side panels and two end panels. The internal chassis support assembly (ICSA) as seen in Figure 16, the main subassembly of the chassis, contained 50 roller assemblies mounted in two aluminum channels that provided support to the tread belt and absorbed the footfall force. Eight roller assemblies were mounted to the three cross support beams, which along with an additional four black side roller assemblies mounted in the side panels, provided support to the tread belt [1].

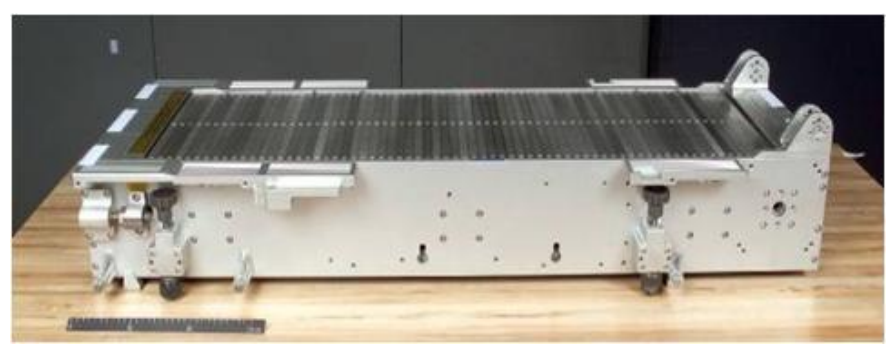

Figure 13. Treadmill Assembly (Chassis) 


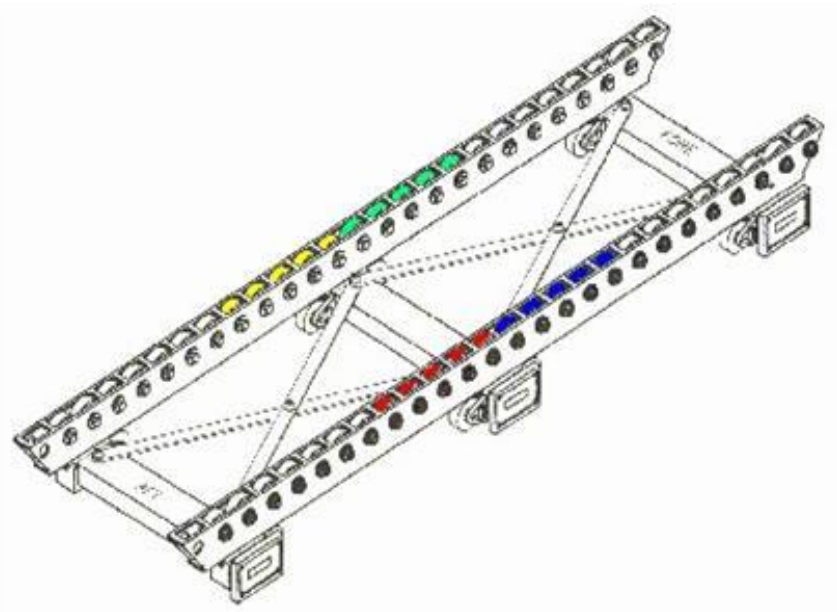

Figure 14. ICSA Diagram

The running surface of the treadmill, the tread belt assembly, was composed of several subassemblies, which included the endless belt, slat assembly, pan-head screws, and weld nuts. The tread belt assembly consisted of a flexible belt with 159 individual rigid slats, which were attached to the upper Neoprene rubber side of the belt (Figure 17).

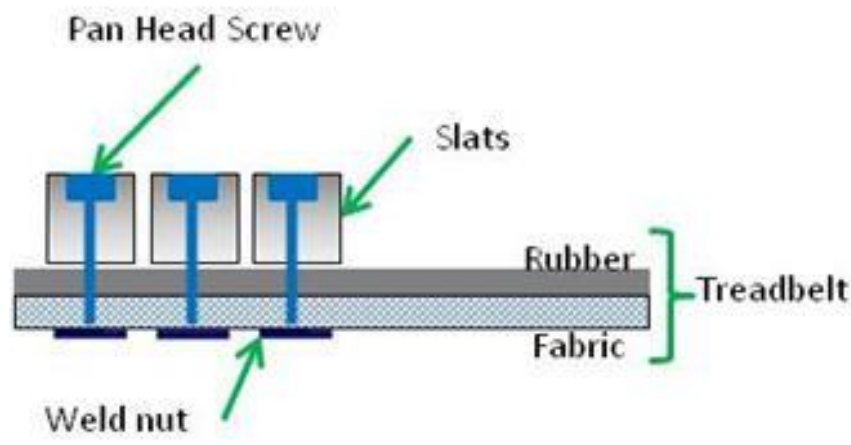

Figure 15. Tread Belt Stack-up Nominal Configuration

1) Broken Tread Slats

In March 2001, the crew reported that some Ultem 2000 slats on the TVIS chassis had cracked during use (Figures 18 and 19). Pictures were sent to the ground for evaluation, and TVIS was declared NO GO for use. Upon evaluation, engineers on the ground determined that the slat design had negative margins of safety for stress and fatigue. The slats were subsequently redesigned and machined from aluminum (Figure 20). The aluminum slats were certified, flown and installed, and never experienced this failure again in the lifetime of TVIS operations [17].

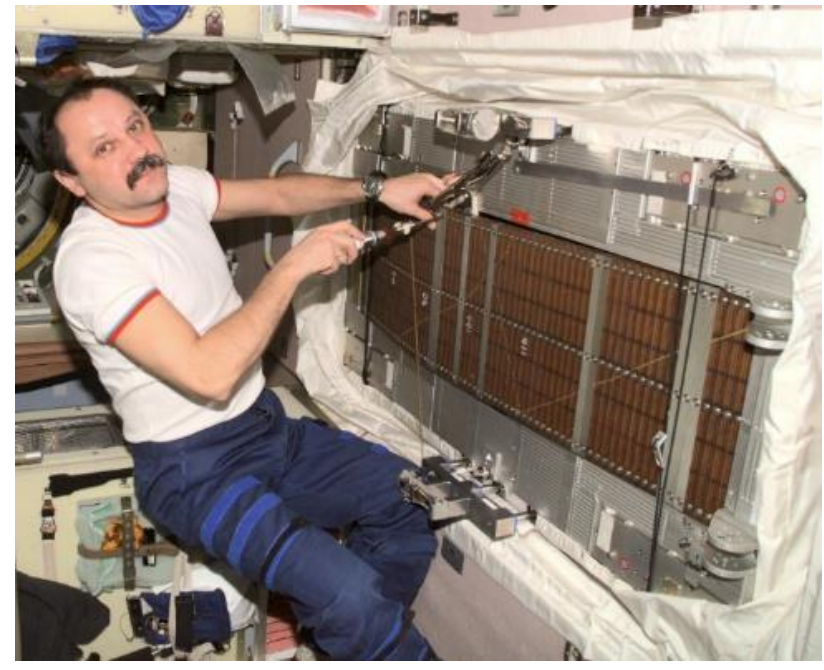

Figure 16. TVIS Chassis on ISS

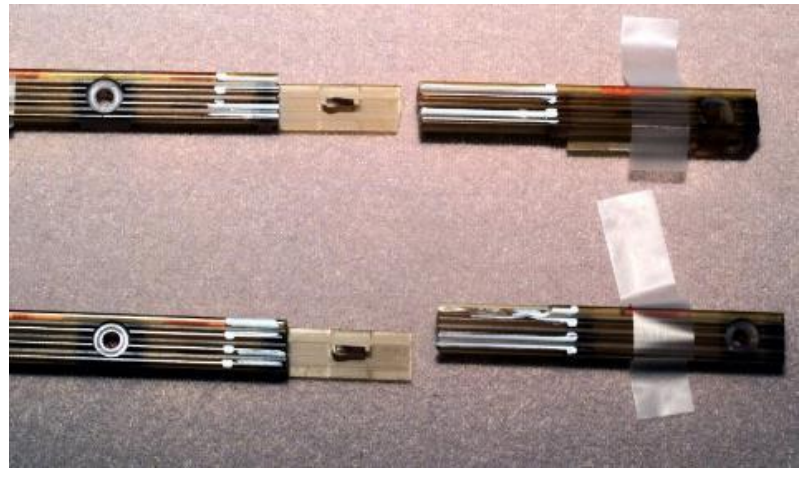

Figure 17. Broken Ultem 2000 TVIS Slats

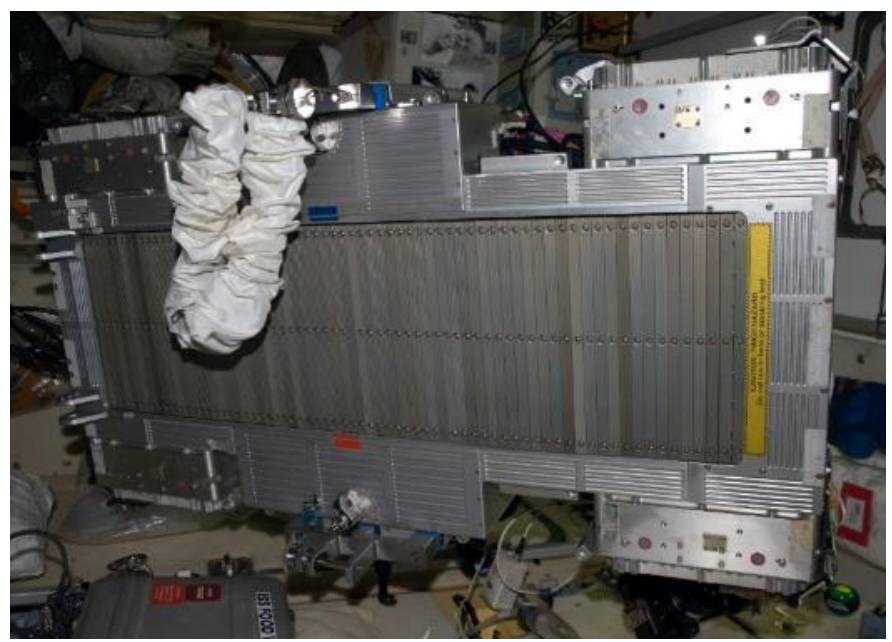

Figure 18. TVIS with New Aluminum Slats

2) Chassis Rollers and Bearings

First, during post-flight visual inspection of the chassis in July 2002, an egg-shaped hole was found in the truss where a roller shaft mounts (Figure 21). On-orbit troubleshooting revealed two similar holes in the truss on-orbit. The root cause of the damage was determined to be a failed bearing that seized on its shaft. When the bearing failed, it caused the shaft to begin spinning within its mounting hole. The steel shaft began to eat 
away at the aluminum truss and created the egg-shaped hole. The failed bearings were sent to the NASA Materials and Processes (M\&P) group for analysis, and they determined that the bearings had insufficient lubrication and were underrated for this application.

Second, the crew reported a failure with the chassis rollers in October 2007. The ICSA with the missing roller can be seen in Figure 22 below. They had approximately 660 hours of use (2 years) at the point of failure, but were certified by analysis to a limited life of 2000 hours. That analysis was based on KC-135 test flight data that demonstrated the loads observed at the rollers within the treadmill. Using that data in an analysis, the center 10 rollers on each side of the chassis would need to be replaced every 500 hours, whereas the remaining rollers should last 2000 hours. Since a roller outside the center 10 rollers failed on-orbit after 660 hours, it was concluded that the analysis assumptions were incorrect, and the design did not have enough margin to accommodate the actual loads applied on-orbit. A design change was made to the roller material and larger bearing in 2009 using a modified skateboard wheel, and the design proved to be robust, never failing or needing replacement. The limited life was set to 500 hours, the same as the previous black roller design since no testing was done. The performance of the new design was trended and monitored, but no damage or significant wear was ever observed, as seen in Figure 23 below, so the life was extended to 1000 hours, and it continued in use without a failure until the TVIS retirement in 2013 [18].

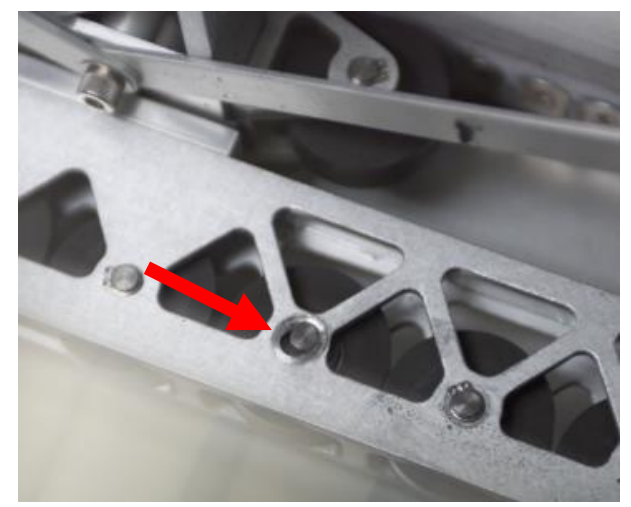

Figure 19. ICSA Damaged due to Seized Bearing

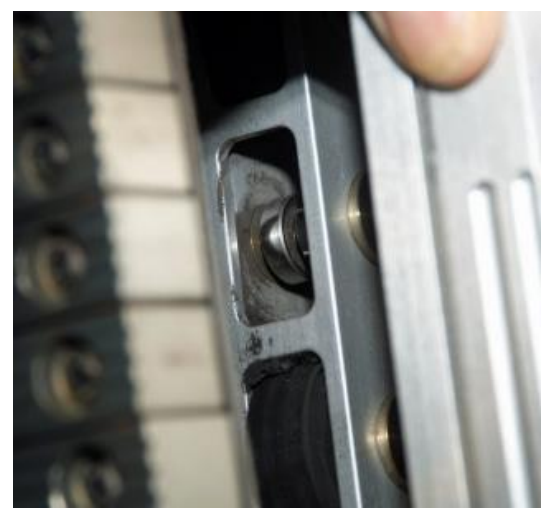

Figure 20. Roller Damage
After the following corrective measures (design changes and procedure changes) were implemented with the new roller assembly design used in the -309 chassis, this anomaly did not reoccur:

- The ICSA was redesigned to eliminate lightening pockets and to use a stronger material (Aluminum 7075).

- D-shaped aluminum bushings on the outboard side were added to increase the load-bearing capacity of the truss as the shape prevents the rotation of the bushing.

- The new truss was designed to allow for on-orbit roller bearing replacement of the bearings that see the greatest load on-orbit.

- The steel bearing shaft was secured to a locking nut.

- Rheolube 2000 was used as a bearing lubricant.

- Crew procedures were modified to regularly inspect for failed bearings [19].

- Treadmill usage was closely tracked and roller assemblies were replaced prior to bearings reaching end of life.

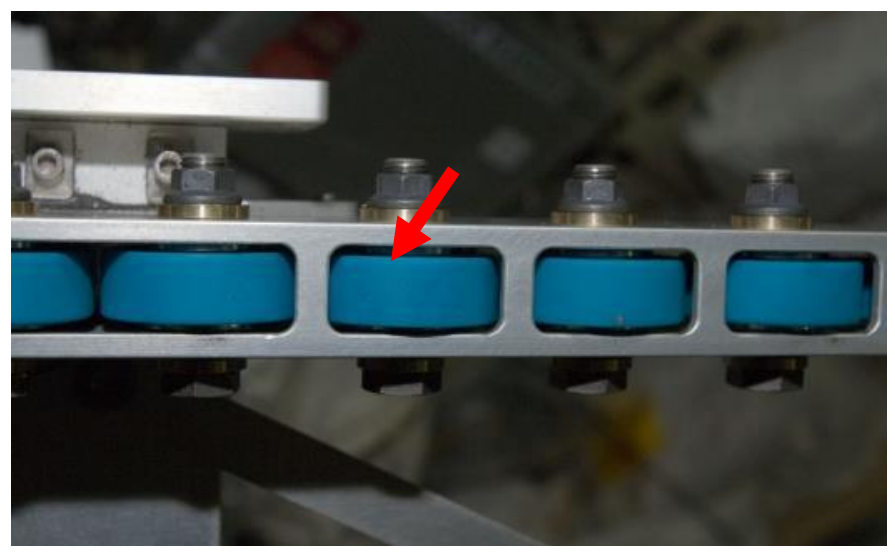

Figure 21. New Roller

\section{b) Stabilizer Springs}

The four stabilizer assemblies were used to stabilize Z-axis and pitch motion of the TVIS System. The stabilizer assemblies were installed onto the treadmill via two captive bolts at each of the four corners of the treadmill chassis. The three main subassemblies of the stabilizer assembly were the motor controller, clamp rope assembly, and the stabilizer (Figures 24 and 25) [1].

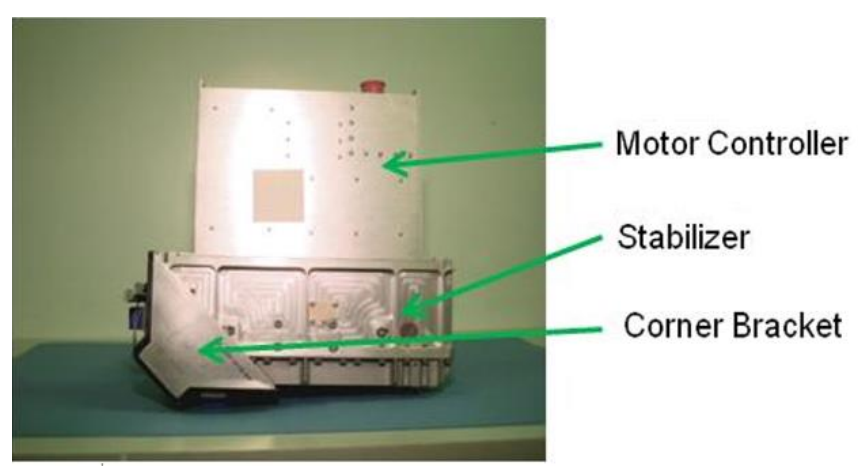

Figure 22. Stabilizer Assembly 

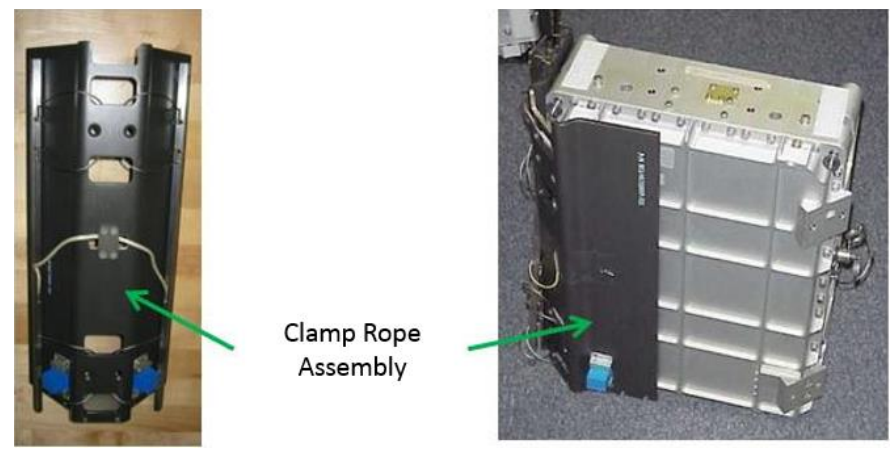

Figure 23. Stabilizer and Clamp Rope Assembly

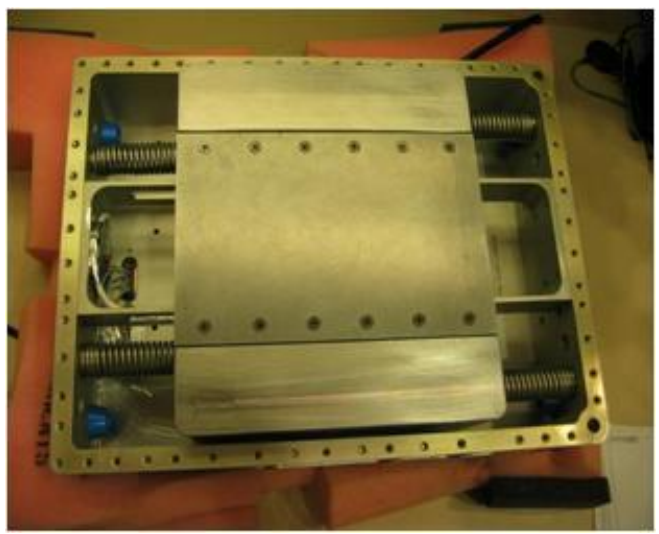

Figure 24. Stabilizer - Cover Removed

The stabilizer was comprised of an aluminum housing, rare earth magnets with a stainless steel back plate, and stainless steel bearings. The stabilizers had an actively controlled mass spring motor system with a natural frequency near the average running frequency $(\sim 3.3 \mathrm{~Hz})$. The stabilizers contained a brushless DC linear motor equipped with linear bearings lubricated with Braycote 601, which moved the mass-spring system to provide an equal and opposite force to the footfall forces and to help stabilize above the natural frequency. The internal components of the TVIS stabilizer can be seen in Figure 26 above. The motor controllers contained all of the electronics that controlled the motor movement within the stabilizers.

In May 2009, the crew reported that the TVIS System was making a "clunking" noise in the forward right corner at speeds of 5-6 mph and that the noise corresponded with each footfall while exercising. Troubleshooting determined that the "clunking" noise originated from the forward right stabilizer. After pinning the throw mass to prevent movement, a visual inspection revealed a free-floating spring/flange connector inside the stabilizer cavity. A manned activation and checkout (ACO) activity was conducted, and a review of the data and video identified unexpected vibrations in the chassis, degradation of the chassis stability, and a "thumping" noise (indicative of the throw mass within the remaining three powered stabilizers being overdriven), thus increasing the risk of mechanical damage occurring to the remaining three active stabilizers.
On June 5, 2009 the forward and aft right stabilizers were disconnected from the TVIS System by the ISS crew, and their covers were removed. Internal inspections of the forward right stabilizer revealed that one of the four springs had failed and the spring/flange connector fasteners that attached the spring to the throw mass had also failed (Figure 27). The spring/flange connector fastener heads and spring/flange connector with part of the broken spring were removed from the forward right stabilizer and the cover was reinstalled. No damage was found during internal inspection of the aft right stabilizer. Both stabilizers were reinstalled on June 2009, and an ACO consisting of a "shake test" for all four stabilizers was conducted to identify any additional loose parts within the cavities. Following the unmanned and manned ACO, the TVIS System was put back into use on-orbit; however, the system was in a degraded state until ground spares could be assembled and flown.

In order to prevent additional spring failures and to return the TVIS System to a nominal operating configuration, four spare springs were flown on flight $2 \mathrm{~J} / \mathrm{A}$ and installed in the forward right stabilizer in September 2009. During the April 2010 Annual Maintenance, a new forward right stabilizer assembly was installed and springs were changed-out with flown spares in the remaining three stabilizers. Additionally, during the scavenge activity on the forward right stabilizer assembly, the crew reported an additional failed spring, which was removed prior to re-stowing the stabilizer on-orbit as a "scavenge-onneed" spare unit. Engineering believes that the possible cause of the additional failed spring in the stabilizer was due to two broken springs identified in the forward left stabilizer during the change-out activities. The forward left stabilizer spring failures potentially caused the remaining stabilizers to work harder (increasing load and spring extension and decreasing the natural frequency of the VIS System) and may have contributed to the premature failure of the spring in the forward right stabilizer [20-22].

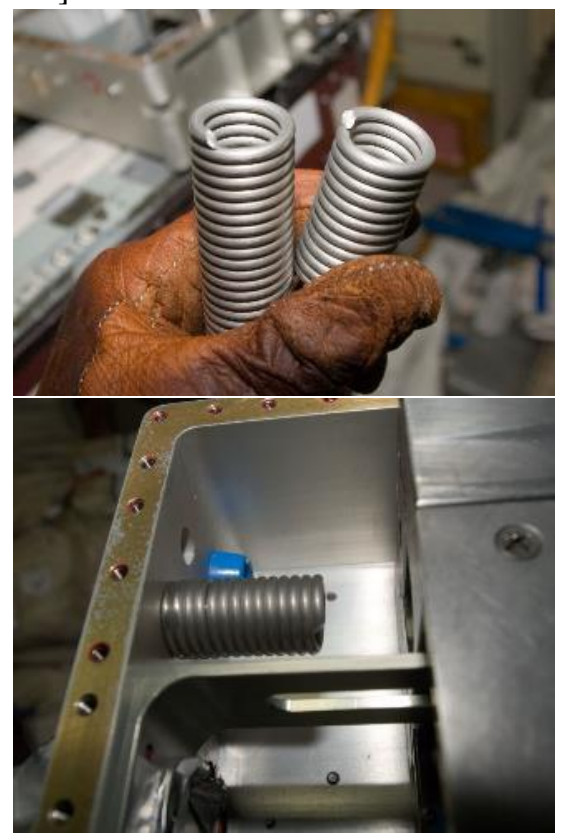

Figure 25. Broken TVIS Stabilizer Springs 
c) Gyroscope

The gyroscope assembly (Figure 28) was used to stabilize the TVIS System from excessive roll during operation and provided current peak smoothing of the TVIS System power sources. The gyroscope flywheel was housed in an aluminum housing. It was designed to spin at approximately $2400 \mathrm{rpm}$ and provided the restoring torque to counter roll torque inputs by the crewmember. An integral brushless DC motor was used to spin the flywheel. Power and speed control for the gyroscope was provided from the VIS controller assembly. The gyroscope was located beneath the treadmill chassis in an area inaccessible to the crew during nominal operations and was attached to the chassis side plates. The gyroscope had a vertical spin axis and pivot bearings positioned in the pitch direction to allow for the required precession during operation. The gyroscope incorporated two (one per side) swaged wire rope assemblies that aided in restoring the gyroscope back to its neutral position and prevent excessive movement [1].

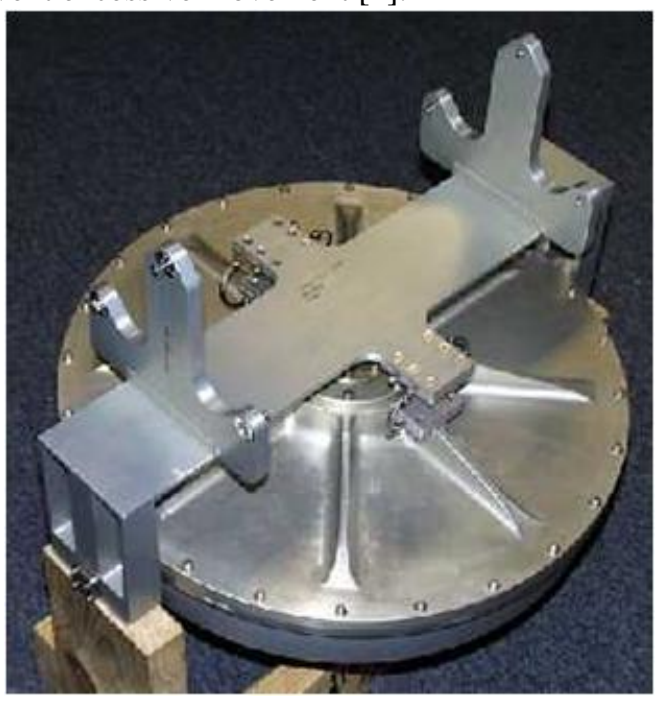

Figure 26. Gyroscope assembly

On November 17, 2003, the crew reported a metal scraping/screeching noise coming from the gyroscope. An In-Flight Maintenance (IFM) was conducted in December 2003 to disassemble the gyroscope. The crew identified that the bearing was degraded (Figure 29), and an investigation of the spare ground gyroscope revealed a similar problem on bearings that had only been used approximately 20 hours. NASA M\&P investigated the problem and determined that the grease inside the bearings had been contaminated and was breaking down and also that the Nitrile material used to seal the bearing has a shelf life of 3 to 5 years. The manufacturer of the bearings initially packed the bearings with a hydrocarbon-based grease. The instructions in a drawing Flag Note indicated that this grease should be removed and the bearings repacked with Braycote 601 grease, but testing showed that the hydrocarbon-based grease was not completely removed on the failed bearings. The remnants of this grease chemically reacted with the Braycote 601 , decreasing its effectiveness. This contamination caused the bearings to fail prematurely. This information was not previously identified by the bearing vendor or found during certification of the hardware. The failed bearings were 7-years old. It is believed the seals failed, allowing the grease to escape, which led to rapid mechanical degradation of the bearings. The TVIS System engineering team assembled a gyroscope repair kit and an in-depth procedure to allow the crew to disassemble the gyroscope and install new bearings. The crew repaired the gyroscope in March 2004, and it operated nominally until it was replaced by a new gyroscope in December 2006. The newly delivered gyroscope included several design improvements. The bearing seals were made of Viton, which did not have a shelf life. Also, the bearing grease was changed to Rheolube 2000 [23-24].

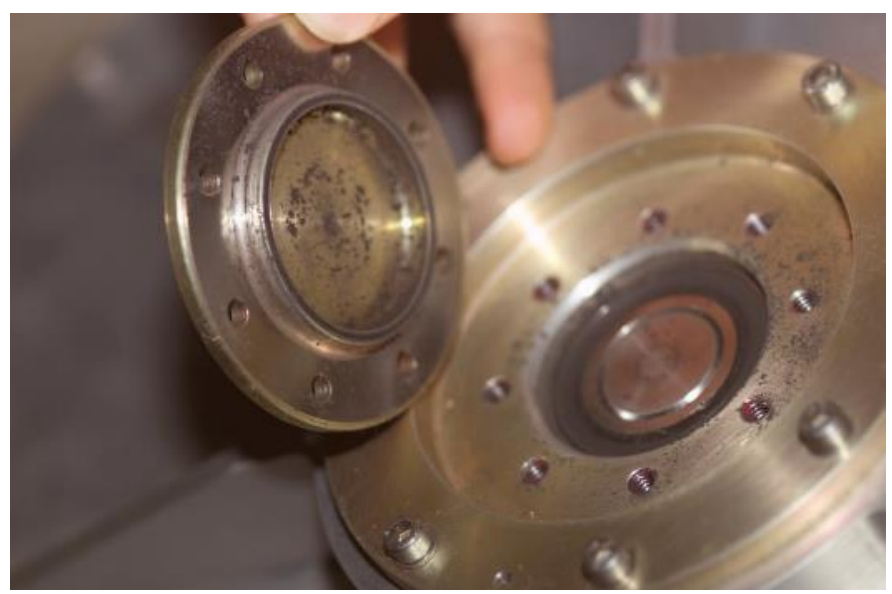

Figure 27. Gyroscope Bearing Debris

\section{Success Stories - Reliable Components}

Given the schedule and budgetary restrictions on TVIS, the ISS Program decided to fly TVIS as a protoflight system and essentially conduct life-cycle testing on-orbit. This created an evolutionary design process, driven by on-orbit failures. As designs failed, were improved, and eventually tested on-orbit, they progressed to a good stage of reliability. Some examples of items that had initial failures and evolved to reliable components include the aluminum tread slats, the redesigned chassis rollers, and the gyroscope bearings. These items never required replacement once the design was studied and modified. The engineering team was able to learn from the failure and make the design robust and as fail-safe as possible.

\section{CEVIS}

\section{Performance History}

CEVIS has been one of the most reliable devices within the CMS system, with failures rarely occurring. Some of this can be attributed to the prior experience with the parent design on the space shuttle, and some of it can be attributed to parts selection, as the parts have proven to be robust.

Table 77 lists the types of failures that might result in NOGO status or failures with operational restrictions. Failures of major components of CEVIS will take it to a NO-GO state, as indicated in the following list, but only for a short time, as CEVIS has spare parts on board to quickly recover from the failures. 
Table 7. NO-GO and Failures with Operational Restrictions - CEVIS

\begin{tabular}{|l|l|}
\hline \multicolumn{1}{|c|}{ NO-GO Failures } & \multicolumn{1}{|c|}{$\begin{array}{c}\text { Failures with Operational } \\
\text { Restrictions }\end{array}$} \\
\hline - $\begin{array}{l}\text { IVIS Boxes - NO GO due to } \\
\text { vibration isolation - first set } \\
\text { lasted 14 years, passive device, } \\
\text { no spares }\end{array}$ & $\begin{array}{l}\text { C Control Panel - CEVIS } \\
\text { Contingency Controller } \\
\text { (CC) available }\end{array}$ \\
- Frame piece - no spare, \\
$\quad$ workarounds not possible \\
- Ergometer - Spares, originally \\
no spare \\
- Pedal - Spares available \\
- Isolators - required for ops, \\
spares available
\end{tabular}

\section{Failure History}

This section will detail the important CEVIS failures that demonstrated lessons learned in reliability.

\section{a) Isolator}

The CEVIS isolators (Figure 30) are wire rope egg-beatertype devices that provide the only structural attachment between the CEVIS frame assembly and the ISS U.S. Lab rack using seat track adapters. They contain 12 strands of wire rope, and an isolator assembly is attached at each of the four corners of the CEVIS frame to minimize the vibrations transmitted from the CEVIS System to the ISS structure during operation. They are changed out on an as-needed basis when more than 8 wire ropes are severed out of 12 on a single isolator. The isolators are inspected every 3 months and have had a service life varying from 1 to 3 years [2].

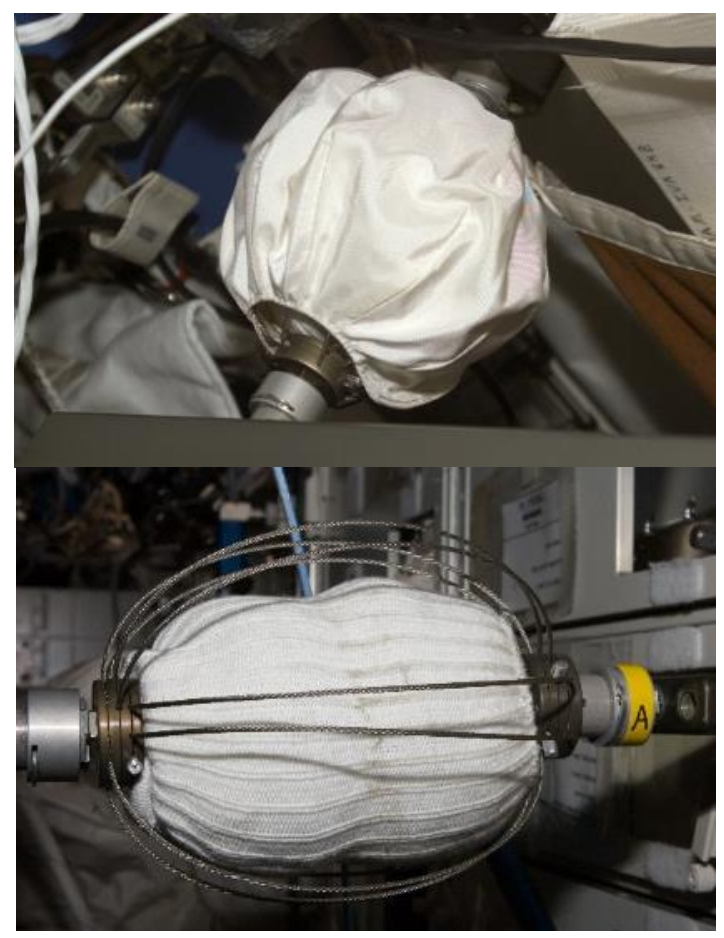

Figure 28. CEVIS Isolators on ISS

Over the service life of CEVIS, inspections are conducted every 3 months to check the status of the isolators. The wire ropes have periodically broken due to fatigue at the clamp point, as a stress concentration exists at that point when the wire ropes are flexed, but they can remain in service if eight or fewer wires are severed. Once the eighth wire breaks, the unit is replaced. The crew on Expedition 6 added rolled sock-balls inside the wire cage to help reduce movement during the EVA exercise pre-breathe activity, which purges the system of nitrogen before a spacewalk is conducted. This requires rigorous pedaling and movement with the arms, which makes the CEVIS riding very unstable without the socks. They also act as bump stops and prevent severe bending of the wire ropes.

The clamp plates of the CEVIS isolator were redesigned in 2011 to add a chamfer to the edge of the hole where the wire rope passes through the plates, thus reducing the stress concentration at that point. Figure 32 below shows the outlet hole of the isolator before the design change, and Figure 33 shows the updated design with the chamfered edge. This small change has increased service life of the isolators substantially, and the true service life is still being evaluated, as only one wire has failed on one isolator in almost 4 years of use. Per Figure 31 , it is evident that the effects of the new design (magenta lines) are a dramatic improvement [25].

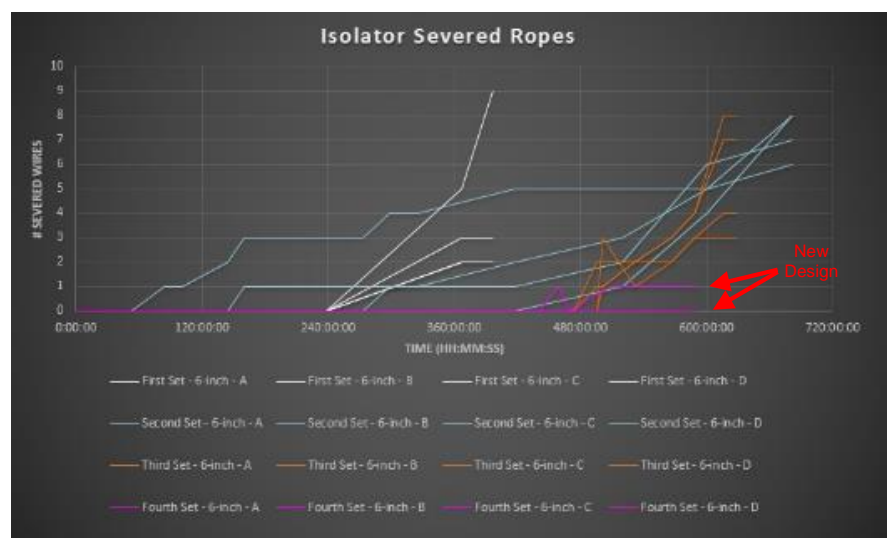

Figure 29. CEVIS Isolator Performance History

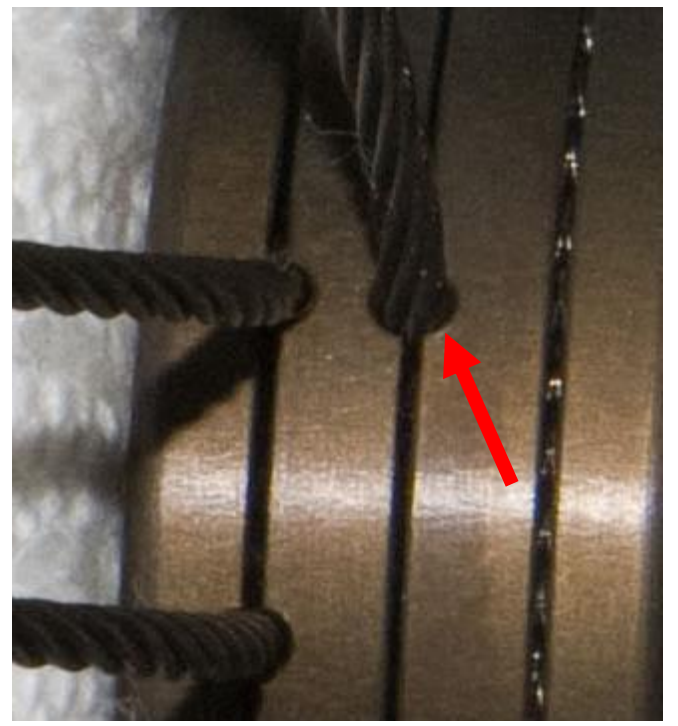

Figure 30. Old Design with no Chamfer on Hole Edges 


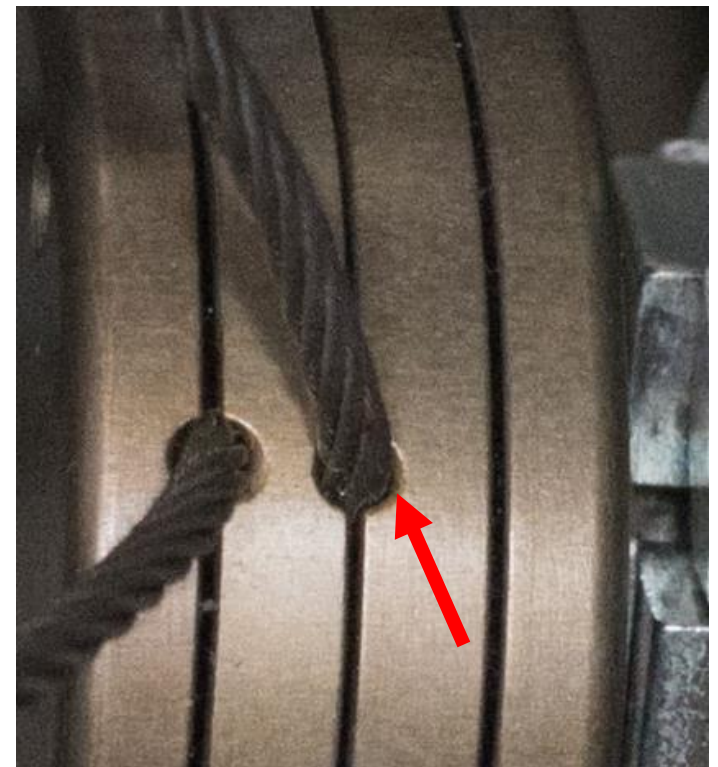

Figure 31. New Design with Chamfer on Hole Edges

\section{b) Control Panel Features}

The CEVIS control panel provides the subject with an interface to the control electronics of the ergometer. It stores data on a portable storage device and is connected to the ISS local area network (LAN). It has a touch screen for crew entry [2].

Key parameters displayed by the control panel include the following:

- Subject selection

- Target cycling speed

- Actual cycling speed

- Target workload

- Actual workload

- Adjusted workload (Rx mode)

- Target heart rate (Rx mode)

- Actual heart rate

- Elapsed time

- Stage time remaining (Rx mode)

- Loaded prescription (Rx mode)

The crew called down in March 2003 that when they tried to power up the CEVIS for exercise, they received a "non-system disk" error and the control panel would not boot up, even after multiple power cycles. The exact cause of this anomaly could not be pinpointed while the control panel was still on-orbit, but engineering suspected that it was due to either a hard disk failure or corrupted software. The crew continued their exercise on CEVIS, but in non-powered, manual mode. After questioning the crew further, it was confirmed that the crew could not get the display to come up at all, the error message had been appearing more frequently when the control panel still worked, and the modes on the screen were very noisy. Because there were no spares on-orbit, engineering concluded that the control panel was "failed" and was not recoverable without launching a replacement unit.

A workaround was developed that enabled the crew to resume powered CEVIS exercise. Using on-orbit power supplies and wire, the crew was able to input voltages to regulate the CEVIS workload and receive feedback data via onorbit voltmeters. A replacement control panel was launched on ULF1.1, and the CCC (Figure 34) was subsequently designed, tested, and certified in case another unexpected control panel failure occurred. The CCC remains stowed on ISS currently [26].

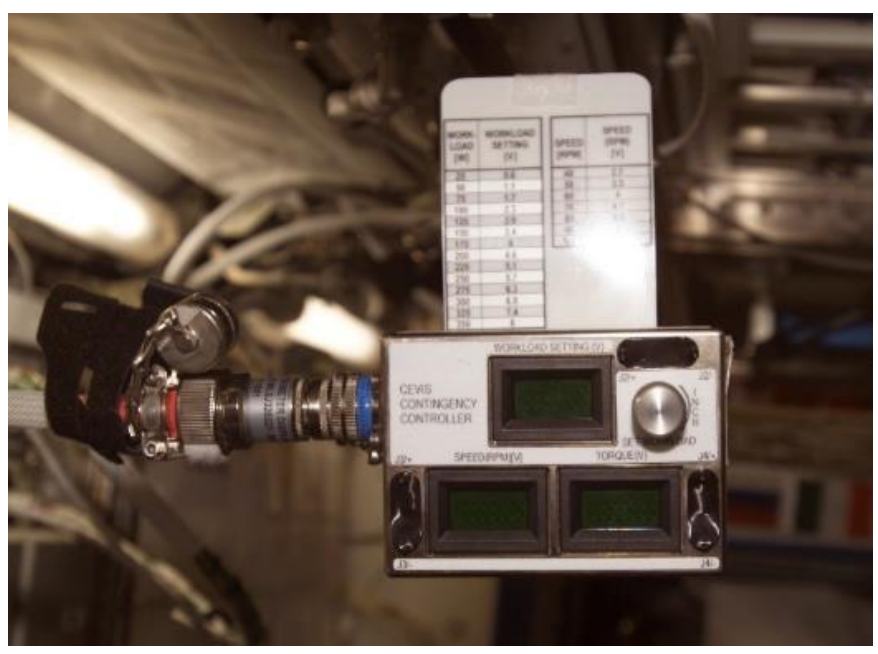

Figure 32. CEVIS Contingency Controller

\section{c) Ergometer}

The ISS cycle ergometer contains the main mechanics and electronics to provide the user with cyclic and arm ergometry exercises. The ISS ergometer is a modified version of the space shuttle IVIS cycle ergometer with the principal difference being the addition of an electronic control system. The gear device, IVIS interface, frame interface, motor coupling, lever, braking band, and manual control systems have all remained unchanged from the shuttle IVIS cycle ergometer. The exposed moving parts consist of crank arms, pedals, handles, and a clevis fixed to a drive rod. The pedals, when rotated, drive a flywheel through a planetary gear set. Friction/resistance is applied to the flywheel by a braking band that is tightened by a spring-tipped ball screw driven by a stepper motor. Feedback from the load beam torque sensor enables the stepper motor to maintain a constant workload. The pedals also drive the clevis fixed to the drive rod of the ergometer. This, in turn, drives the throw masses of the IVIS boxes back and forth to counter forces applied by the crewmember when pedaling. The ergometer houses the main electrical components and supplies the power for the control panel. The manual control knob interfaces with the ergometer during manual mode operations to manually adjust the braking band tension to provide resistance [2].

During the new CEVIS control panel activation and checkout in March 2009, the crew reported seeing the manual control knob message appear when the load decreased from a high workload to a low workload in protocol mode. A review of the new control panel activation and check-out data, PFE and subsequent exercise data revealed a gradual increase in workloads over time with rest periods not returning to baseline. The manual knob function was checked later during ACO and 
verified to be nominal. Subsequent data analysis showed that actual load was not following target workload. When target workload changed from high workload levels to low workload levels, actual workload was significantly greater than target workload. This load discrepancy increased with time over the course of an exercise session. On April 9, 2009, troubleshooting isolated the problem to the ergometer. The crew was directed to stand down on CEVIS operations because load discrepancy indicated potential internal ergometer damage, and the risk associated with continued nominal usage prior to an ergometer internal IFM could result in irreparable hardware damage or failure. Trending data analysis from March 29, 2009 to April 8, 2009 showed the anomaly to worsen over the span of a protocol. Several IFM activities were performed in May 2009 to disassemble the ergometer. Internal sub-assemblies were inspected and determined to be nominal. The braking band, fan, guide rod, and flywheel were all cleaned of dust and debris. The braking band contained some embedded dirt that was later partially removed by brushing and vacuuming. Several internal components were inspected and photographed before reassembling the ergometer. After the ergometer was reassembled, several protocols were run, and the workload drift anomaly and manual knob messages disappeared. Data was analyzed on a weekly basis, and no major issues were identified in the data between June 2009 and middle August 2009. During review of the CEVIS data downlinked in early September 2009, actual workload data did not return to target load as commanded when stepping down from high workload to lower workload. On September 15, 2009, the crew noted that 'Manual Knob Activated' message was displayed on the CEVIS control panel during a large delta in workload. The direct cause of the workload drift was due to the excess friction force from a heated, dirty and worn braking band (Figure 34) to the flywheel, adding additional mechanical resistance to the system. The CEVIS ergometer braking band was replaced with the new braking band that was launched on 17A during an IFM activity on October 5, 2009 (Figure 35). The braking band had been in use on-orbit for approximately 7 years before it was replaced. Data processed weekly since October 2009 supports that the anomaly had been remedied by replacement of the braking band. A braking band limited life of 382 hours was added to the Government Certification Acceptance Request (GCAR) and began to be tracked by the CEVIS team. It is acceptable to exceed the 382 hours if no signs of the anomaly are present [2728].

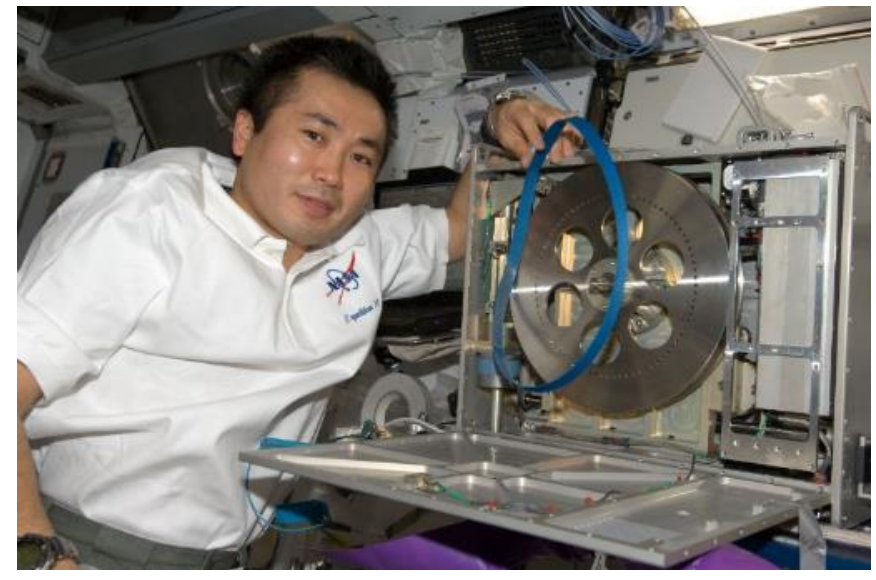

Figure 33. CEVIS Braking Band Replacement

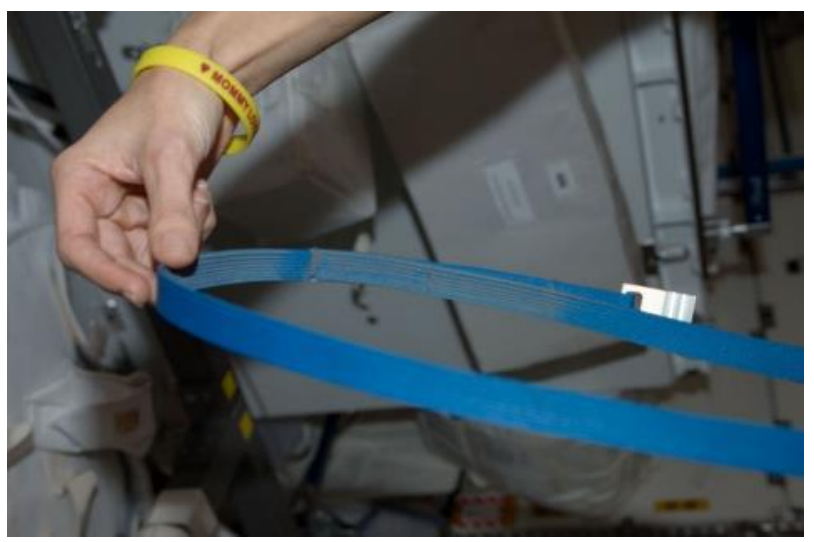

Figure 34. Dirty CEVIS Braking Band

d) Frame

The mounting frame provides the interface between the ergometer and the isolators and can be broken down into eight components, which are stowed for launch and assembled onorbit. It places the CEVIS System above the face of the rack during operations, but allows the ergometer to rotate $90^{\circ}$ counterclockwise via the mounting block and guide pins to a stowed position when not in use. This minimizes the permanent protrusion into the ISS LAB aisle and pathway. The mounting block and guide pin are shown in Figures 37 and 38 below [2].

In May 2002 the Expedition 2 crew reported that the CEVIS was becoming more difficult to rotate into operational configuration. They heard a "scraping/crunching" noise, at which point they stopped and notified the ground. The crew confirmed that the CEVIS was deployed in the operational position, not in the stowed position. Engineering determined that there was binding in the guide pins causing friction during rotation and developed a troubleshooting procedure to help the crew assess the problem. The crew verified that the mounting block was stuck to the mount pins. Engineering determined that the only solution for resolving the issue was replacement of the forward frame, guide pins and mounting blocks. Operations concluded that this configuration was acceptable since it does not impede emergency egress and only slightly impinges on the nominal crew translation path. A material analysis was 
performed on the ground at JSC, which concluded that materials selected in this application did not have good compatibility for galling prevention. The damaged guide pin and mounting block bushing can be seen in Figures 39 and 40 below. The materials group recommended the use of a lubricant, Braycote $601 \mathrm{EF}$, to reduce the risk of galling in the future. Before on-orbit implementation, the revised configuration with Braycote 601EF was successfully cycletested on the ground the equivalent of 2 years on-orbit use. From the time of failure in 2001 until 2006, the crew used CEVIS in the deployed position, and it was kept in operational position until the new frame was flown on ULF1.1. Yearly maintenance to lubricate the guide pins and mounting block bushings was implemented in July 2006 and continued every year thereafter [29].

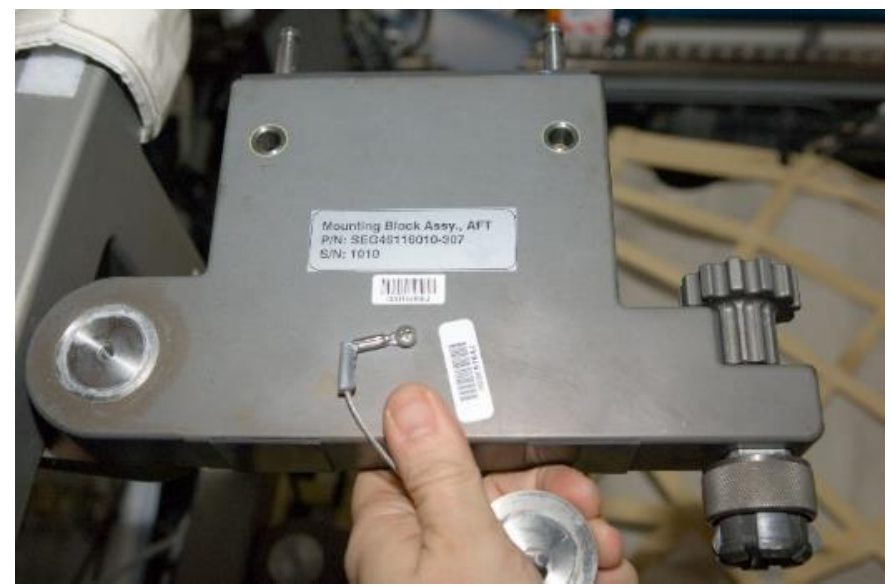

Figure 35. CEVIS Mounting Block

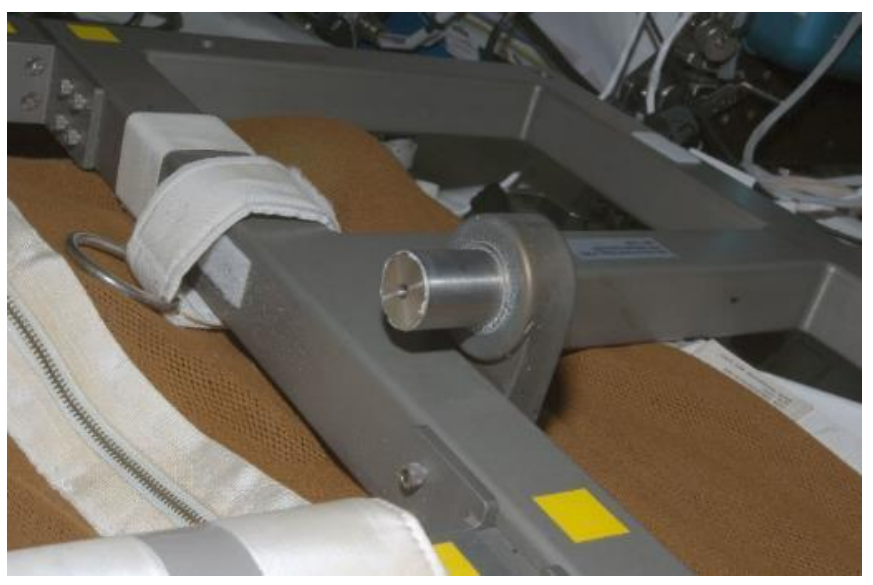

Figure 36. CEVIS Guide Pin

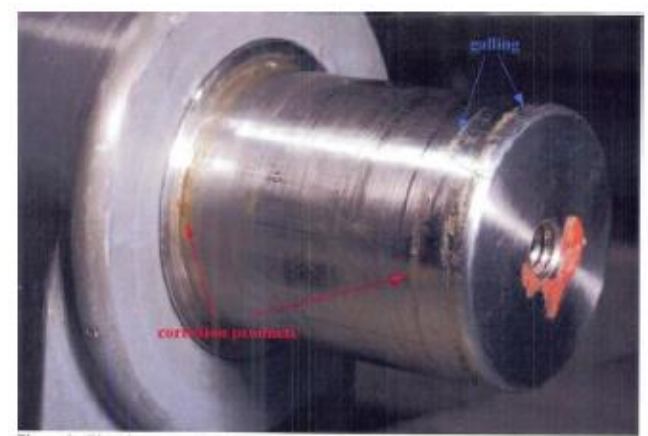

Figure 37.CEVIS Guide Pin

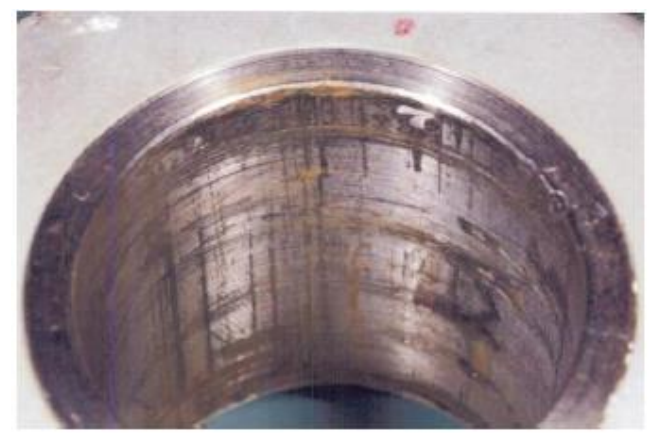

Figure 38. CEVIS Bushing and Guide Pin Damage

\section{Success Stories - Reliable Components}

Given the schedule and budgetary restrictions on CEVIS, the ISS Program decided to fly CEVIS as a protoflight system and essentially conduct life-cycle testing on-orbit. This created an evolutionary design process, driven by on-orbit failures. Even with the low rate of failures on CEVIS, as designs failed, were improved, and eventually tested on-orbit, they progressed to an even better stage of reliability. Some examples of items that had initial failures and evolved to reliable components include the CEVIS isolators after the outlet chamfer was added to the clamp plates and the mounting block and guide pin interface after Braycote 601EF grease was added. These items have not required replacement since the designs were modified. The engineering team was able to learn from the failure and make the design robust and as fail-safe as possible.

\section{$V$. ANALYSIS}

Studying the failure and success examples of the CMS hardware systems can assist in the selection of criteria and processes that lead to good reliability. Depending on the function of the system, it could be a single criterion or a combination of many. The following sections detail these criteria and processes that can be used in the hardware development life cycle to help maximize reliability [5].

\section{A. Robustness}

Robustness is an important quality in successful hardware and software systems in any spaceflight application. It is defined as the degree of tolerance to variations in either the components of a system or its environment. It is often defined 
as the toughness of a system under variable conditions. Items that are robust, such as the ARED structure and exercise bar hardware system which have never failed, require little to no maintenance and are expected to last for the duration of the mission without replacement. The robustness of a system design can be predetermined on the ground, and confidence in a design can be gained via the following techniques:

\section{Life Cycle Testing/Scatter Factor}

Life-cycle testing operates a system under normal conditions to determine a service life. NASA uses a scatter factor of 2 for non-safety critical items and a scatter factor of 4 for safety critical items, which means that for every 2 or 4 cycles in the life-cycle test, only one cycle counts towards the actual service life on-orbit. This protects the system from variances in hardware and conditions to provide ample time for spares to be manufactured and delivered to space. It also determines the worst-case maintenance interval for replacement. The experience with the CMS hardware demonstrated that life-cycle testing with scatter factor is a very reliable way to protect capability on-orbit and is one of the best ways to predict maintenance and resupply schedules so that failures do not affect operations or crew health.

\section{Factor of Safety}

The factor of safety is a design margin above the calculated ultimate strength or yield of a material. By utilizing a factor of safety in an analysis, the engineering team can ensure a design is built to sufficient margins so that structural failures are not even possible within defined usage conditions. Again, the ARED structure is a good example, as it has positive margins within all structural components. The structure is classified as fail-safe due to these margins, as the process to replace the frame and structure on-orbit is not feasible from a budgetary or crew time standpoint.

\section{Independence from Functional Instrumentation}

Systems often rely on instrumentation to function, and while the data provides valuable insight into the condition of a system, electrical systems are often the point of failure for hardware. Using the CEVIS and ARED as examples, where instrumentation systems failed (CEVIS control panel and ARED AIB), the systems were able to continue operations, and availability was sustained. The CEVIS could operate in manual mode, and the ARED could function without the AIB, as crewmembers entered data manually into spreadsheets. This independence from the instrumentation systems allowed exercise to continue. When designing hardware, this should be considered, as these redundancies allow systems to adapt, bypass the failure state, and resume operations.

\section{Contingencies/Workarounds}

Contingencies plans and workarounds have been the lifesaver for CMS hardware through the years. A contingency or back-up plan can be by design or out of necessity. By design, some systems have contingency hardware. For example, CEVIS has the CCC in case a control panel fails. By necessity, an innovative solution is devised using available supplies as a reaction to a failure. An example is tying back the ARED upper stop cable with a cable tie when it fails to bypass the failure on lower stop exercise. These contingencies allow the hardware to remain functional and provide the intended capability to the crewmembers. Sometimes a contingency is not possible, but by thinking and planning for failures, the response to implement a contingency can be relatively short if the required materials are available.

\section{B. Instrumentation}

Predicting failures before they actually happen by careful design of instrumentation is key to keeping hardware available to crew. Instrumentation provides insight to a system's condition via strategically placed sensors in areas that can isolate problems. It often increases the cost of an item, so the designer must have solid rationale as to why the data is needed. Consideration to power consumption must be taken, as to not violate an item's allotted power footprint. The location, data rate, and accuracy of the sensors must also be chosen to provide useful trending, warnings, and timely alerts so that a response can be applied before an actual failure occurs. Examples of useful instrumentation within CMS were the CEVIS braking band anomaly and the TVIS Gyroscope bearing failure. By having sensors in the right place within the system, the engineers were able to analyze data and form a successful troubleshooting plan with likely causes. This greatly reduced the crew time required to troubleshoot the problem and allowed the time to be devoted to actual repairs.

\section{Crew Feedback}

Feedback from crewmembers is a valuable tool in assessing the health of CMS hardware. The crew uses the hardware daily, so after a short time on-orbit, they become in-tune with how it functions and quickly ascertain what is normal from a feel and sound standpoint. Crewmembers are trained with the CMS hardware for years before their missions. Training allows them to become familiar with the operations and maintenance activities, and it attempts to normalize how the hardware is used and what conditions it experiences with humans in the loop. Sometimes the human factor can introduce variations to the CONOPS based on an individual's interpretation of how the device should be used, so when planning designs, these offnominal conditions should be considered and sufficient margins applied. Examples would be the Kevlar TVIS corner ropes breaking due to not being strong enough to endure actual onorbit running and the ARED Polyester exercise rope splice coming apart under zero load conditions as crew handled the end of the rope. These could have been prevented had variations in the normal operations been considered. Crew feedback can also point out failures that were not anticipated, such as the more recent ARED upper stop cables. The crew noticed the frayed cable and reported the effects, and the ground team produced and worked through a fault tree to determine the root cause. Without the crew's observations, the failure would have been more sudden and impacts to operations abrupt. By the crew giving a warning of the damage, the ground team was able to prepare a plan to replace the cable when it failed before the actual failure occurred. 


\section{Maintenance and Sparing}

Maintenance and sparing is critical in systems with limited life components. Knowing all of the limited life items within a system via test or analysis provides an advantage to keeping systems operating and increasing reliability and availability. As demonstrated in the first few years of TVIS operations, unknown limited life on the tread slats, bearings, rollers, stabilizer springs, and stabilizer corner wire ropes resulted in significant down-time on the system, unexpected resupply of spare components, and impacts to crew time to conduct the replacement activities. When deep space missions begin, with limited stowage volume and mass available for spare parts, knowing the life of the system components will be critical to mission success. Spares will not be in close proximity, and a failure of a part without spares will most likely result in permanent NO GO.

\section{LESSONS LEARNED}

By studying the failures of CMS hardware, trends were identified, leading to lessons learned. First, life-cycle testing the hardware before deployment is the only way to accurately predict failures and ensure the right number of spare parts are stowed on ISS. Using scatter factor, the maintenance schedule can help protect against unexpected failures and keep the hardware available for use. When a project has funding and schedule available prior to flight, they should always life-cycle test the hardware to gain this insight. Second, material incompatibilities can result in damage to hardware during operations, which can lead to failures, as experienced with the TVIS gyroscope, TVIS chassis roller bearing, and CEVIS guide pin and bushing. When materials are interfaced and experience movement, the materials, grease, bearings, etc. should be scrutinized by industry experts to ensure the best choices are made and reliability is maintained. Third, having ample spare parts on board will keep hardware operational and minimize downtime. Although this is closely related to life-cycle testing and understanding the maintenance interval, for hardware that is being flown for the first time, it would be prudent to maintain some spares of components that are single-point failures if stowage volume and mass limits allow. Good examples are the CEVIS control panel and the ARED crank handle, relatively small items that could have been flown and stowed with little impact and prevented multiple days of NO-GO conditions on the hardware. The final lesson learned is that smart, strategically placed instrumentation is key to troubleshooting problems and quickly recovering from a failure. This will become more important as missions venture farther and farther from Earth, as replacement hardware, if possible at all, will be years away instead of months or days. Most likely, replacements will not be available, so a quick diagnosis and recovery plan must be formulated and executed by the crew. Instrumentation should allow quick isolation of the problem so valuable crew time will not be wasted.

\section{CONCLUSION}

Reliability issues in ISS exercise CMS hardware has produced lessons learned as well as success stories. As failures occur, they drive designs to evolve and improve to ultimately reach a point of utmost reliability. Designers of future systems can utilize the resources, examples, and techniques discussed in this paper and achieve better success in keeping hardware operational for crewmembers. When deep space missions begin, system reliability and availability will be more important than ever, as failures will have greater consequences. 


\section{ACRONYMS}

$\mathrm{ACO}$

AIB

ARED

CCC

CEVIS

\section{CMS}

CONOPS

EEE

EVA

GCAR

ICSA

IFM

ISS

IVIS

JSC

$M \& P$

NASA

NPD

ORU

PIP

R\&M

SBS

SLD

SM

SPD

SSP

TVIS

USB

VIS

VIS

and Stabilization

Electronic

Request

Administration

Push-in-Place

Service Module

Stabilization

Universal Serial Bus and CEVIS)
Activation and Checkout

ARED Instrumentation Box

Advanced Resistive Exercise Device

CEVIS Contingency Controller

Cycle Ergometer with Vibration Isolation

Countermeasures System

Concept of Operations

Electrical, Electromechanical, and

Extra-Vehicular Activity

Government Certification Acceptance

Internal Chassis Support Assembly

In Flight Maintenance

International Space Station

Inertial Vibration Isolation and Stabilization

Johnson Space Center

Materials and Processes

National Aeronautics and Space

NASA Policy Directive

Orbital Replacement Unit

Reliability and Maintainability

Series Bungee System

Subject Load Device

Subject Positioning Device

Space Station Program

Treadmill with Vibration Isolation and

Vibration Isolation and Stabilization (TVIS

Vibration Isolation System (ARED)

\section{REFERENCES}

[1] R. Ambrose, P. Bevill, M. Murray, S. Reddy, D. Blank, and H. Goetz, "Sustaining Engineering Description for the Treadmill with Vibration Isolation and Stabilization (TVIS) System," NASA JSC63712, Rev. B, 2011.

[2] R. Ambrose, P. Bevill, R. Eid, C. Reyes, and T. Moore, "Sustaining Engineering Description (SED) for the Cycle Ergometer with Vibration Isolation and Stabilization (CEVIS) System," NASA JSC63334, Rev E, 2014.

[3] R. Ambrose, P. Callen, C. Maynard, C. Latour, L. Thackston, "Advanced Resistive Exercise Device (ARED) Sustaining Engineering Plan," NASA JSC62541, Rev. C, 2014

[4] KSC Reliability, http://kscsma.ksc.nasa.gov/Reliability/

[5] Engineering Design Reliability Handbook, CRC Press, Boca Raton, FL, 2004.

[6] NASA Systems Engineering Handbook, NASA/SP-2007-6105 Rev 1, December 2007

[7] NASA Reliability and Maintainability (R\&M) Program, NASA Policy Directive (NPD) 8720.1

[8] Qualification and Acceptance Environmental Test Requirements, SSP 41172, Revision U, March 2003

[9] FIAR JSCER0148F, G. Szymczak, LAU Crank Handle Primary Lock Pin Fails to Engage, 2012

[10] FIAR JSCER0149F, G. Szymczak, ARED Load Changes Spontaneously, , 2012

[11] FIAR JSCER0152F, H. Goetz, ARED Crank Handle Assembly Adapter Failure, 2012

[12] FIAR JSCER0156F, H. Goetz, ARED Crank Handle Assembly Identified Loose, 2013

[13] FIAR JSCER0176F, H. Goetz, ARED Crank Handle Assembly Identified Loose, 2013

[14] FIAR JSCER0217F, L. Thackston, ARED Crank Handle, 2014

[15] FIAR JSCER0078F, J. Go Boncan, Dashpot bracket Assembly Rod (pin) Came Loose and Backed Off From the Rocker Arm (paddle), 2009

[16] FIAR JSCER0158F, H. Goetz , ARED Instrumentation Box (AIB) Failure, 2011

[17] FIAR JSCEA50115F, R. Toler, TVIS Slats Broken, 2001

[18] FIAR JSCEA0016F, W. Dyer, Roller Bearing Inside TVIS Chassis Broke Into Pieces, Causing The Treadbelt To Jam, 2007

[19] FIAR JSCEB0067, R. Senegal, Seized Bearing,2002

[20] FIAR JSCER0075F, A. Robinson, Broken spring in TVIS Forward Right Stabilizer S/N 1004, 2009

[21] FIAR JSCER0102F, P. Bevill, One spring found broken in TVIS Forward Right Stabilize, 2010

[22] FIAR JSCER0105F, M. Allen, Two springs found broken in TVIS forward left stabilizer, 2010

[23] FIAR JSCEB0168F, R. Senegal, TVIS (Treadmill Vibration Isolation System) Noise., 2003

[24] FIAR JSCEB0188F, M. Iwasa, Nitrile Seal On TVIS Gyroscope Bearing Suspected To Have Exceeded Shelf Life., 2004

[25] FIAR JSCEB0336F, T. Schmidt, CEVIS Isolators Broken, 2005

[26] FIAR JSCEB0123F, R. Senegal, CEVIS Does Not Boot Up On Power Up, 2003

[27] FIAR JSCER0069F, C. Langat, CEVIS Workload Anomaly And Manual Knob, 2009

[28] FIAR JSCER0083F, C. Langat, CEVIS Workload Drift Anomaly And Manual Knob Error, 2009

[29] FIAR JSCEA50118F, R. Senegal CEVIS Deploy Position Problem, 2001 